\title{
Precipitation and temperature of the southwest Caspian Sea region during the last 55 years: their trends and teleconnections with large-scale atmospheric phenomena
}

\author{
M. Molavi-Arabshahi, ${ }^{a *}$ K. Arpe ${ }^{\mathrm{b}, \mathrm{c}}$ and S. A. G. Leroy ${ }^{\mathrm{c}}$ \\ a Ocean Sciences Research Center, Iranian National Institute for Oceanography and Atmospheric Science, Tehran, IR Iran \\ b Department of Meteorology, Max Planck Institute for Meteorology, Hamburg, Germany \\ ${ }^{\mathrm{c}}$ Institute for the Environment, Brunel University, London, UK
}

\begin{abstract}
Climate data from the southwest coast of the Caspian Sea (CS) were statistically analysed to find connections with large-scale atmospheric variabilities and regional impacts. The study area is characterized by a subtropical humid climate. This enclave of high precipitation is extremely important for Iranian food production and is recognized for its high biodiversity.

The data sets were investigated for inconsistencies before carrying out the main investigations, and several problems have been identified. The results show three distinct climatic periods in the temperature time series since 1956: 1956 to 1975 with values near to the overall mean, 1977 to 1995 with values lower by $0.5^{\circ} \mathrm{C}$ and from 1996 to 2010 with values higher by $0.5^{\circ} \mathrm{C}$. These periods can be positively correlated with rapid sea level changes of the CS. Moreover, an agreement exists between the three climatic periods and the North Atlantic Oscillation (NAO) variability. The sea surface temperature of the southern CS is shown to be the driving force of the $2 \mathrm{~m}$ temperatures in the study area. While temperature changes are in accordance with NAO variability, the precipitation variations show connections with ENSO and less with NAO. The trends of precipitation during the period are diverse but display mostly a weak decrease, while the trends of temperature display a clear increase, larger than that for global mean temperatures, overlaid with inter-decadal variations.
\end{abstract}

KEY WORDS climate change; SW Caspian Sea region; teleconnections; ENSO; NAO; ECMWF interim reanalysis; GPCC

Received 16 November 2014; Revised 20 July 2015; Accepted 21 July 2015

\section{Introduction}

Long-term observational data are essential for detecting and understanding climate change at local, regional and global scales. Predictions of climate change due to human-induced increases in greenhouse gases and aerosol concentrations are an ongoing discussion (IPCC, 2013). In recent years, the integration of observational data and modelled data via assimilation techniques has yielded a new generation of data sets for advanced research (Feng et al., 2004).

Information about temporal and spatial variabilities in temperature and precipitation time series is extremely important not only from the scientific point of view but also for future mitigation plans. Moreover, meteorological and oceanographic studies require accurate temporal and spatial temperature and precipitation inputs in analysing climate change impacts and adaptation and in validating climate simulations. The detection of abrupt or gradual changes in temperature and precipitation records has recently become of increasing interest in the scientific

\footnotetext{
* Correspondence to: M. Molavi-Arabshahi, Ocean Sciences Research Center, Iranian National Institute for Oceanography and Atmospheric Science, No. 3, Etemadzadeh St., Fatemi Ave., Tehran 1411813389, IR Iran. E-mail: molavi.arabshahi@inio.ac.ir
}

community (Kundzewicz, 2004; Kundzewicz and Robson, 2004).

In order to be able to derive significant conclusions about such changes, long time series of climate data are needed. However, continuous accurate long-term time series are difficult to obtain, as modifications to instrumentation and small site changes can have profound effects on climate data (De Jongh et al., 2006). Points of discontinuities in time series, which can result from, for example, changes in observation locations, equipment, measurement techniques and environmental changes, need to be detected.

The geographical focus for this study is the SW coast of the Caspian Sea (hereafter CS), in the Guilan Province of Iran. The SW coastal area of the CS with up to $1850 \mathrm{~mm}$ annual precipitation has an obviously different climate from the rest of Iran, with an average of $250 \mathrm{~mm}$ precipitation per year. Moreover, the region of interest has one of the highest precipitation levels of SW Asia. This region, due to its mild subtropical humid climate, has a prosperous agricultural yield and is one of the centres of food production of Iran (Kosarev et al., 1994; Kosarev, 2005). In addition, it has considerable biodiversity (Akhani et al., 2010). It also served as refuge for plants and animals during the Last Glacial Maximum (Leroy and Roiron, 1996; Arpe et al., 2011). Hence it is essential to understand how its climate is changing as part of current global changes, 
in order to prepare adequate mitigation measures. It is of greatest importance to know in advance the likely climatological developments in this sensitive area. A first step for this is the investigation of past climate to validate climate simulation models, which here are complicated by the complex orography. This area is also much affected by CS level (hereafter CSL) oscillations that have been shown to be linked to the climate-related variations in the basin and to have a relationship with El Niño Southern Oscillations (ENSO) (e.g. Arpe et al., 2000; Nazemosadat and Cordery, 2000; Nazemosadat and Ghasemi, 2004; Arpe and Leroy, 2007).

Some investigations in the field of climate studies, such as those of Wu et al. (2001), for detecting drought and wet periods at different time scales use monthly precipitation totals. Wu et al. (2001) compared the advantages and disadvantages of the application of several statistical indices. The latter study showed that the $Z$-index is a good tool to define, detect and monitor droughts and floods. Kutiel et al. (1996) identified and compared dry and wet years, seasons and sequences at four eastern Mediterranean stations using circulation types. They calculated correlations between precipitation and zonal and meridional indices for understanding large-scale impacts on the area.

Scientists have also tried to find connections between local climate and large-scale phenomena. A circulation anomaly over Europe was already well known before reliable numerical weather forecasts and meteorologists in Germany called it 'omega with cold feet'. It was named after the $(\Omega)$ contour shape of the $500 \mathrm{hPa}$ height field, which is accompanied by cold air outbreaks with precipitation over the western and eastern Mediterranean. Such a pattern enabled more reliable weather forecasts because of its long persistence. Other names are 'Omega-situation' or, more generally 'blocking' (Elliott and Smith, 1948) and nowadays it is associated with 'modes' and 'patterns'. Ghasemi and Khalili (2008a) showed in their figure 5b the anomalous $500 \mathrm{hPa}$ height fields during wet winters in Iran, which correspond to the Omega pattern over Europe. While the western branch of this anomaly is partly represented by the North Atlantic Oscillation (NAO), Kutiel and Benaroch (2002) and Kutiel et al. (2002) investigated its eastern branch and found a 'North Sea-Caspian Pattern - NCP' which shows, not surprisingly, a high correlation with temperature and precipitation anomalies over the Middle East. However, their investigation is limited to the west of our target area, with indications that its impact may be weak over Iran. However, a clear connection was found for winter temperatures for Iran by Brunetti and Kutiel (2011). Ghasemi and Khalili (2008a) found the best linkage between the Black Sea mean sea level pressure (MSLP) and the dominant precipitation variability along the CS coast (PC4 - our target area), expressed by correlation coefficients varying from 0.43 to 0.57 .

The goal of this study is to investigate the climate data SW of the CS for inconsistencies, trends and connections with large-scale variabilities. The outline of this paper is as follows. In Section 2, we discuss our data and characteristics of the study area. In Section 3, we briefly discuss and analyse the $2 \mathrm{~m}$ temperature (T2m) and precipitation data, separating evidence of real climate change from observational errors. In Section 4, we discuss our findings for the southwest $\mathrm{CS}$ region in relation to large-scale climatic phenomena such as ENSO, the NAO and NCP. In Section 5, we report brief conclusions.

\section{General characteristics of the study area and data}

Guilan Province is situated in the north of Iran. It has a surface area of $14711 \mathrm{~km}^{2}$, and is located between $36^{\circ} 36^{\prime} 12^{\prime \prime}$ and $38^{\circ} 27^{\prime} 10^{\prime \prime} \mathrm{N}$ latitude and from $48^{\circ} 43^{\prime} 18^{\prime \prime}$ to $50^{\circ} 34^{\prime} 11^{\prime \prime} \mathrm{E}$ longitude (Figure 1(a)). We confined our study area to the southwest of the CS and to five synoptic stations: Astara, Anzali, Rasht and Lahijan in Guilan Province and Ramsar at its border with Mazandaran Province. These stations are on or near the coast of the CS and are assumed to represent the general state of the southwestern CS. The maximum distance between the five stations is that between Astara and Ramsar, i.e. $310 \mathrm{~km}$.

\subsection{Introduction to the study area}

The CS is the largest inland body of water on Earth, has a surface area of $360000 \mathrm{~km}^{2}$ and a basin of 3.5 million $\mathrm{km}^{2}$. Due to its vast area, the lake is referred to as 'Sea' in the literature. The CS has about a third of the average salinity of seawater, so it is not actually the largest freshwater lake. The CS is fed by 130 rivers, the most significant being the Volga, which enters from the north and accounts for about $80 \%$ of the inflowing waters. In spite of the inflow of freshwater, the lake remains salty, especially towards its southern end. The CS has no outlets, and in consequence loses water only through evaporation, a process that compensates for the dilution of its salinity by the rivers. Today the CSL is around $26.5 \mathrm{~m}$ below mean sea level. Owing to its land-locked nature, the CSL has fluctuated repeatedly during its geological lifetime, including during the last centuries (Naderi Beni et al., 2013). The Iranian coastline in the south CS, stretching over $800 \mathrm{~km}$, contains approximately $18 \%$ of the whole Caspian coastline. The Guilan Province is composed of lowlands, adjacent to the CS, and the western parts of the Alborz Mountains.

\subsection{General climate characteristics of the study site}

The ecoregional climate of our study area is humid subtropical. The northern CS lies in a moderately continental climate zone, while the middle (and most of the southern) CS lie in the warm and dry continental belt. The CS climate is mainly influenced by its geographical position, the prevailing regional atmospheric circulation and the steep orography near some of its coasts. The southern CS is located at low latitudes, so it receives a significant amount of solar radiation. The climate of the study area is influenced by the Alborz Mountains in the south, the Caucasus Mountains in the west and deserts and steppes in the east and north. The main air masses that determine weather 
(b)

(a)

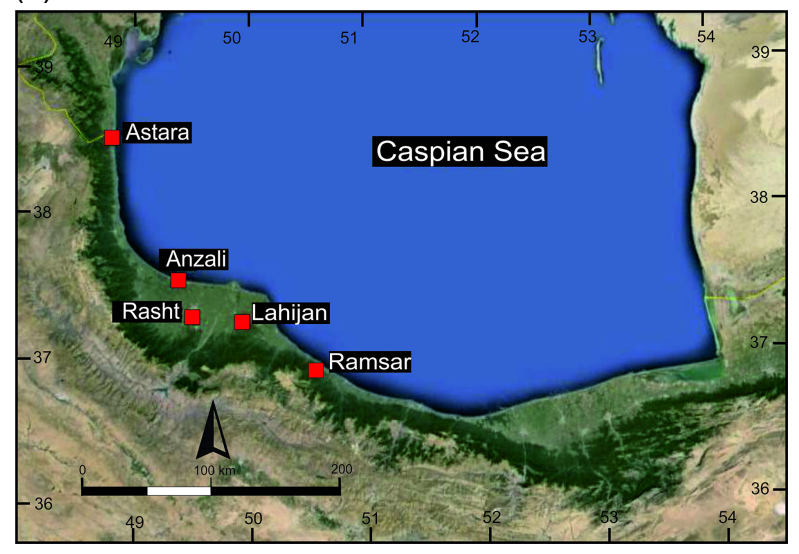

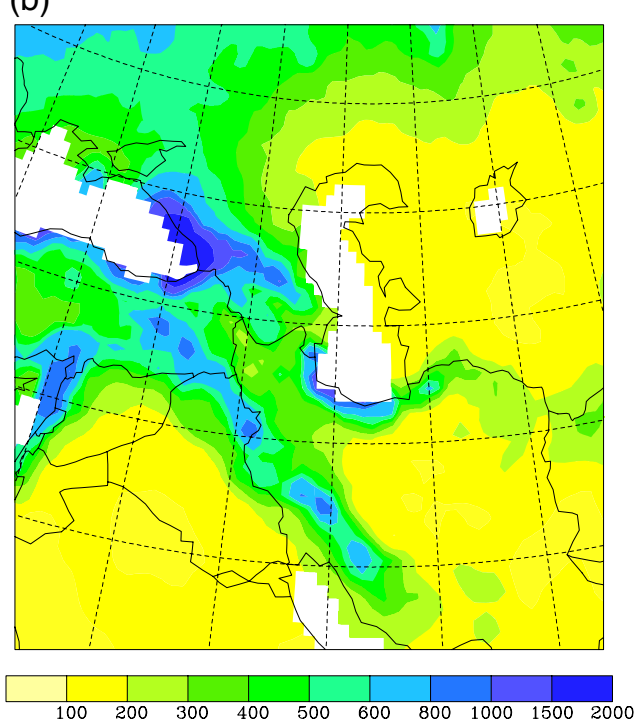

Figure 1. Topography and precipitation around the study area. (a) Position of the five synoptic stations in the Guilan Province (Google Earth). (b) Annual precipitation (mm) from GPCC (2013) on a $0.5^{\circ}$ grid.

Table 1. General characteristics of the five synoptic stations.

\begin{tabular}{|c|c|c|c|c|c|}
\hline Stations & Anzali & Ramsar & Rasht & Lahijan & Astara \\
\hline Elevation (m) & -23.6 & -20 & -8.6 & -2 & -18 \\
\hline Latitude N & $37^{\circ} 29^{\prime}$ & $36^{\circ} 54^{\prime}$ & $37^{\circ} 12^{\prime}$ & $37^{\circ} 11^{\prime}$ & $38^{\circ} 25^{\prime}$ \\
\hline Longitude E & $49^{\circ} 27^{\prime}$ & $50^{\circ} 40^{\prime}$ & $49^{\circ} 39^{\prime}$ & $50^{\circ} 00^{\prime}$ & $48^{\circ} 52^{\prime}$ \\
\hline Mean annual temperature $\left({ }^{\circ} \mathrm{C}\right)$ & 16.2 & 16.1 & 16.0 & 16.0 & 15.4 \\
\hline Maximum annual temperature $\left({ }^{\circ} \mathrm{C}\right)$ & 19.2 & 19.4 & 20.5 & 21.4 & 18.7 \\
\hline Absolute maximum summer temperature $\left({ }^{\circ} \mathrm{C}\right)$ & 28.0 & 27.7 & 33.7 & 33.3 & 28.2 \\
\hline Absolute minimum summer temperature $\left({ }^{\circ} \mathrm{C}\right)$ & 21.6 & 21.1 & 15.2 & 14.8 & 20.2 \\
\hline Minimum annual temperature $\left({ }^{\circ} \mathrm{C}\right)$ & 13.2 & 12.8 & 11.3 & 11.0 & 11.7 \\
\hline Absolute minimum winter temperature $\left({ }^{\circ} \mathrm{C}\right)$ & 5.2 & 4.8 & -2.4 & -0.75 & 3.6 \\
\hline Absolute maximum winter temperature $\left({ }^{\circ} \mathrm{C}\right)$ & 10.3 & 11.1 & 22.6 & 22.4 & 9.9 \\
\hline Annual precipitation (mm) & 1850 & 1212 & 1344 & 1450 & 1344 \\
\hline
\end{tabular}

Dashed lines mean absence of data.

conditions over the sea are cold Arctic masses, humid temperate air masses from the Atlantic Ocean, dry and cold winds from the Siberian anticyclone crossing Kazakhstan and subtropical warm air masses from the Mediterranean and Iran in decreasing order of importance (Baidin and Kosarev, 1986; Martin-Vide and Lopez-Bustins, 2006).

Over the Caspian area, July to August average temperatures vary between 24 and $26^{\circ} \mathrm{C}$, with a maximum of $44^{\circ} \mathrm{C}$ on the sun-baked eastern shore. Monthly average temperatures during winter range from $-10{ }^{\circ} \mathrm{C}$ in the north to $10{ }^{\circ} \mathrm{C}$ in the south (Rafferty, 2011).

The total precipitation along the coast of Iran varies between $1850 \mathrm{~mm}$ for Anzali (Figure 1(b); Table 1) in the west and $<200 \mathrm{~mm}$ in the east. A comparison with the average annual precipitation of Iran $\left(250 \mathrm{~mm}\right.$ year $\left.{ }^{-1}\right)$ highlights the very special climate of our study area: the rainiest part of the country. The CS itself lies in an area of generally low precipitation (Fig. 1(b)); only the mountain ranges of the Caucasus and Alborz show deviations from it. Very high precipitation levels are found along the SW coast of the CS. The highest precipitation (Figure 2) occurs in autumn, followed by winter and spring.

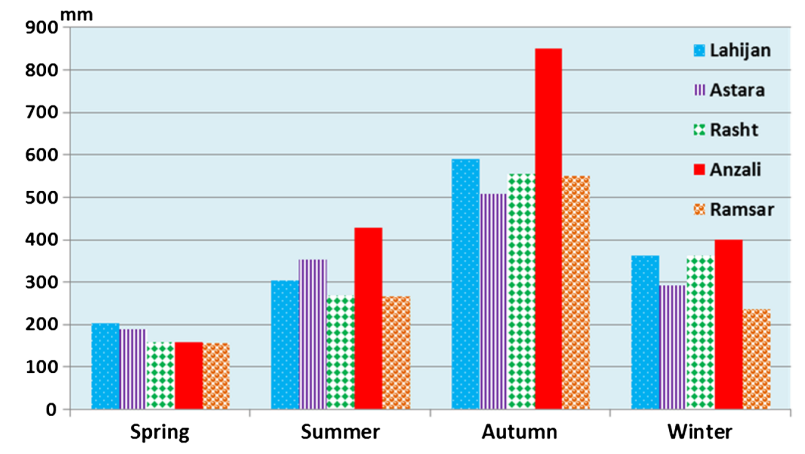

Figure 2. Seasonal precipitation at the stations of Lahijan, Astara, Rasht, Anzali and Ramsar.

Leroy et al. (2011) showed that, for the southern CS area, the wind blows in autumn mostly from the $\mathrm{N}$ to $\mathrm{NE}$ and then is forced up the mountain barrier along the coast. At the same time, the wind above the mountains ( $700 \mathrm{hPa}$ and above) blows from the west and descends down the mountains towards the CS. The updraft from the north-easterly surface winds does not occur exactly at 
(a)

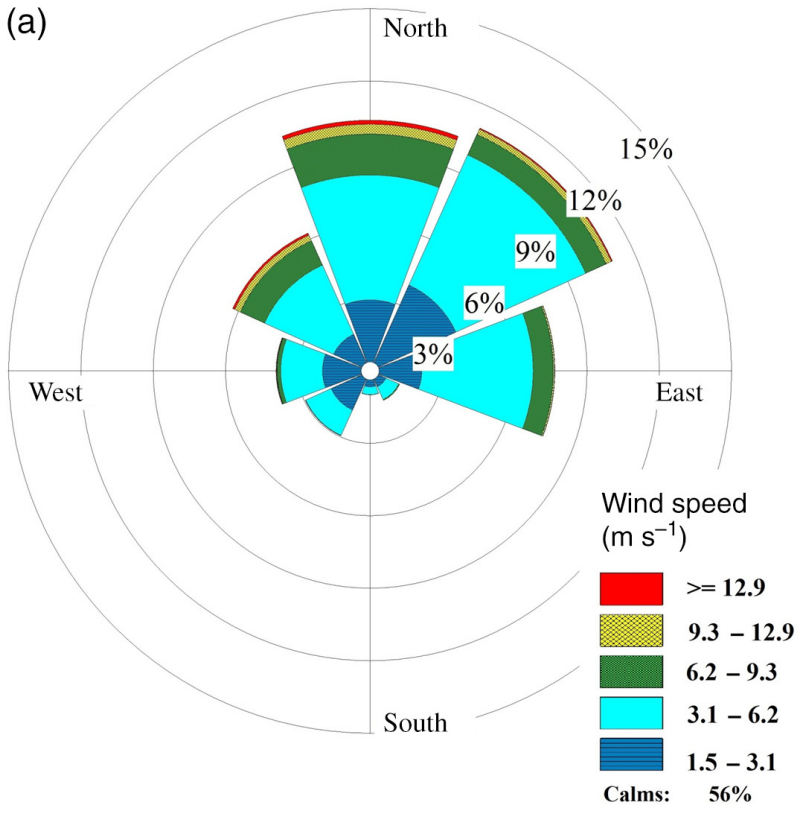

(b)

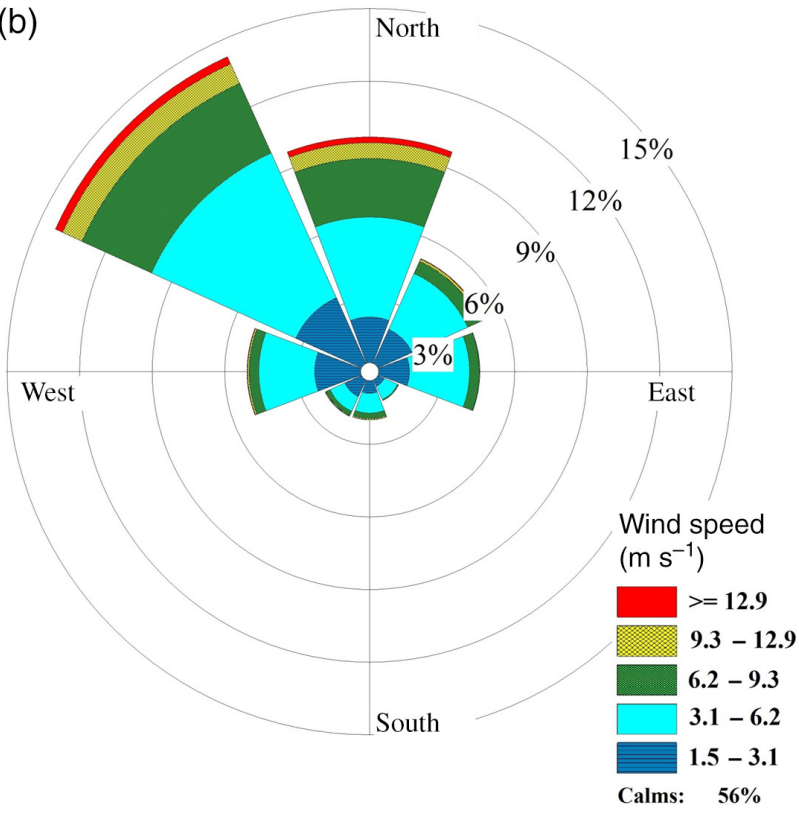

Figure 3. Wind rose diagram for summer (a) and winter (b) seasons of Anzali station with about $56 \%$ calm days in both seasons.

(a)

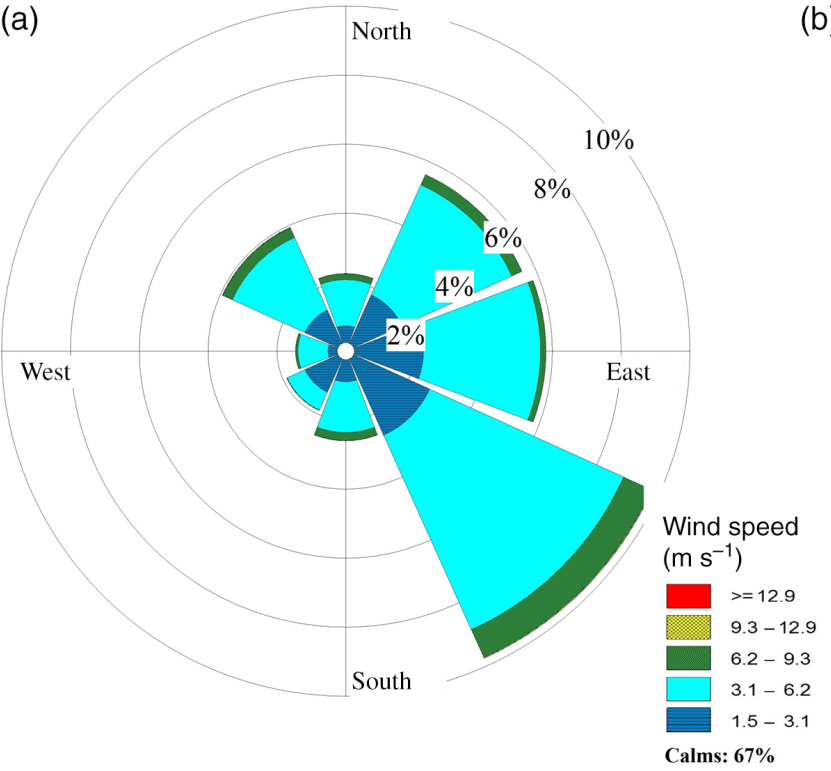

(b)

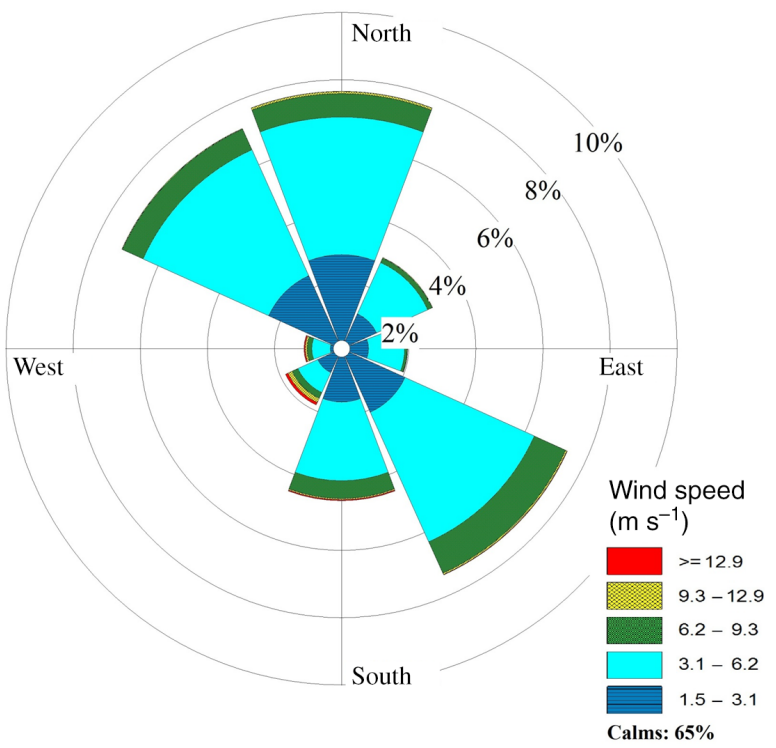

Figure 4. Wind rose diagram for summer (a) and winter (b) seasons of Astara station with $67 \%$ calm days in summer and $65 \%$ calm days in winter.

the slope of the mountains but at some distance towards the sea because of the downdraft. Therefore, the highest precipitation occurs at the Anzali station (on the coast) and not at Rasht or Lahijan, which are closer to the mountains (Figure 2).

The variety of wind conditions on the CS is due to its latitudinal extension, different orographic characteristics around the sea and different weather systems converging on this area. The mean wind speed is lowest in the southern part of the CS $\left(2.5-3 \mathrm{~m} \mathrm{~s}^{-1}\right)$, stronger in the central area $\left(4-5 \mathrm{~m} \mathrm{~s}^{-1}\right)$ and on the eastern coast $\left(3.5-4 \mathrm{~m} \mathrm{~s}^{-1}\right)$. Seasonal means of wind speed across the year (Figures 3 and 4) vary due to the various atmospheric processes on the CS, the different thermal regimes of the sea and the land, and the distribution of mountains. The wind roses in Figures 3 and 4 are based on the maximum length of available data for each station; the differences between the stations in the figures are not dependent on the averaging periods. Anzali lies right at the corner between the two mountain ranges where northerly as well as easterly winds create an updraft; while at Astara only easterly winds will cause an updraft, which might explain why the highest precipitation amounts occur in Anzali. The prevailing westerly winds at higher levels ( $700 \mathrm{hPa}$ or higher) descend down the mountains and confront the north-easterlies at the surface over the CS. From Figures 3 and 4, it seems that the downward descending winds reach Astara and Anzali more often in winter than in summer and that Anzali is more protected in 


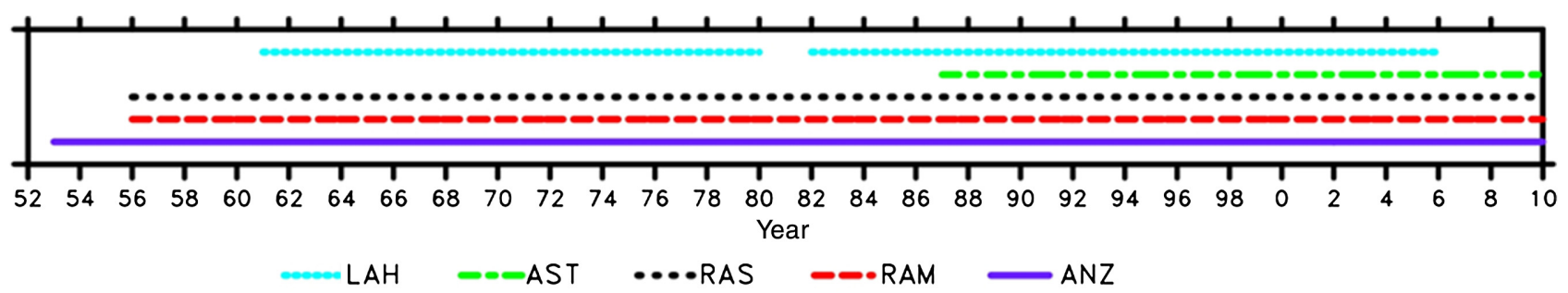

Figure 5. Periods when observational temperature data are available at different stations. LAH, Lahijan, AST, Astara; RAS, Rasht; RAM, Ramsar; ANZ, Anzali.

the south by the Alborz Mountains and therefore has less frequent southerly winds.

In brief, Guilan Province has the highest precipitation for the whole of the CS perimeter, and also for the whole of Iran. At the scale of SW Asia, it is exceeded only on the eastern coast of the Black Sea (Figure 1(b)).

\subsection{Data and methods}

The data for this study were obtained from the Meteorological Organization of Iran (MOI) and the Iranian National Institute for Oceanography and Atmospheric Science (INIOAS). These data include long-term time series between 1951 and 2011 from monthly data of minimum, maximum and mean temperature measured at $2 \mathrm{~m}$ height (T2m), and precipitation. The periods of observational data differ between the stations (Figure 5), Anzali started in 1953 (partly in 1951), Rasht and Ramsar in 1956, Lahijan in 1961 and Astara only in 1986. The data series for precipitation start at the same year as for $\mathrm{T} 2 \mathrm{~m}$ but continue until 2011. For further calculations, we use the 1956-2010 period or the longest available within this period. Only annual means are used.

The relationships of climate data of the CS to each other and parameters such as NAO, ENSO, NCP and sea surface temperature (SST) are investigated. The CDO (2014) package and SPSS software were used for the analysis. Other statistical methods, such as Pearson and Spearman and $Z$-index, were also used.

Some general and climatic characteristics for the five stations are given in Table 1 for the longest available period within 1956-2010.

\section{Results}

\section{1. $2 \mathrm{~m}$ temperatures}

Climatological data (annual means) for the SW corner of the CS are available from two sources: (a) IRAN A (2014) and (b) IRAN B (2007). They contain the synoptic or climate stations of Anzali, Rasht, Lahijan, Ramsar and Astara, among others. The data of (a) have fewer missing values than those of (b), are more recently issued (assuming that possible errors found in the data have been evicted) and are therefore more suitable for further investigations. Figure 6(a) shows time series of the five stations. In Figure 6(b), the differences between Rasht or Lahijan and the means of Anzali and Ramsar are considerable, i.e. up to $2^{\circ} \mathrm{C}$ in $1970-1972$ for Rasht and in $1963 / 1965$, 1974, 1979 and 1990 for Lahijan. Such large differences are unlikely for stations so near to each other. When comparing the data for the same station from the two sources with the means of Anzali and Ramsar in Figure 6(b), much smaller differences are found in the older probably more original data set for Rasht and (except in 1990) also for Lahijan. For Lahijan, the data set (b) has too many gaps to be useful.

The variability in all stations should be very similar because of their close proximity. Astara is further away and has only a short time period of data and therefore we use it only occasionally for comparison.

Lahijan lies on slightly higher ground, very near to the Alborz Mountains (Table 1), and turned out to have a different variability from that of the other stations, which may not be real. Therefore, for the most part, we will omit this station in the following investigation. The time series of Anzali and Ramsar vary very similarly but with mostly lower values $\left(0.5^{\circ} \mathrm{C}\right)$ for Ramsar, except for the period up to 1960 when we find higher values for Ramsar. The drop of T2m at Anzali from 1958 to 1960 was much smaller than that at all other stations (Figure 6(a)).

The differences between the two data series for Rasht are investigated in Figure 6(b). The data series (b) has values above those of all other stations until 1975, after that it fits well with the others until 1995, and especially well with Ramsar but stays below them after that. The data set (a) for Rasht shows a trend opposite to (b). After extremely low temperatures in 1969 in all stations (Figure 6(a)), they all regain the normal value very quickly except for Rasht (data set (a)). T2m stays very low in the Rasht data set (a) for three more years with differences from Ramsar of more than $1{ }^{\circ} \mathrm{C}$, which is unlikely. Assuming that the older data set (b) is the more original one, we postulate that the bias in this data set has been recognized and corrected for data set (a) but not perfectly, thus creating problems for 1971 to 1973 . From 1975 onwards, the series (a) fits well with the other stations and we prefer this series; but we are obviously hesitant to use it before 1975 for any trend analysis.

The next investigation concentrates on the temperature at Anzali and Ramsar. At both stations, a steep increase in the temperatures (highlighted by auxiliary lines in Figure 7) occurs around $1995,0.7^{\circ} \mathrm{C}$ at Anzali and $1.2^{\circ} \mathrm{C}$ at Ramsar, using the auxiliary lines that suggest the mean values for three periods and disregarding the short drop from 1992 to 


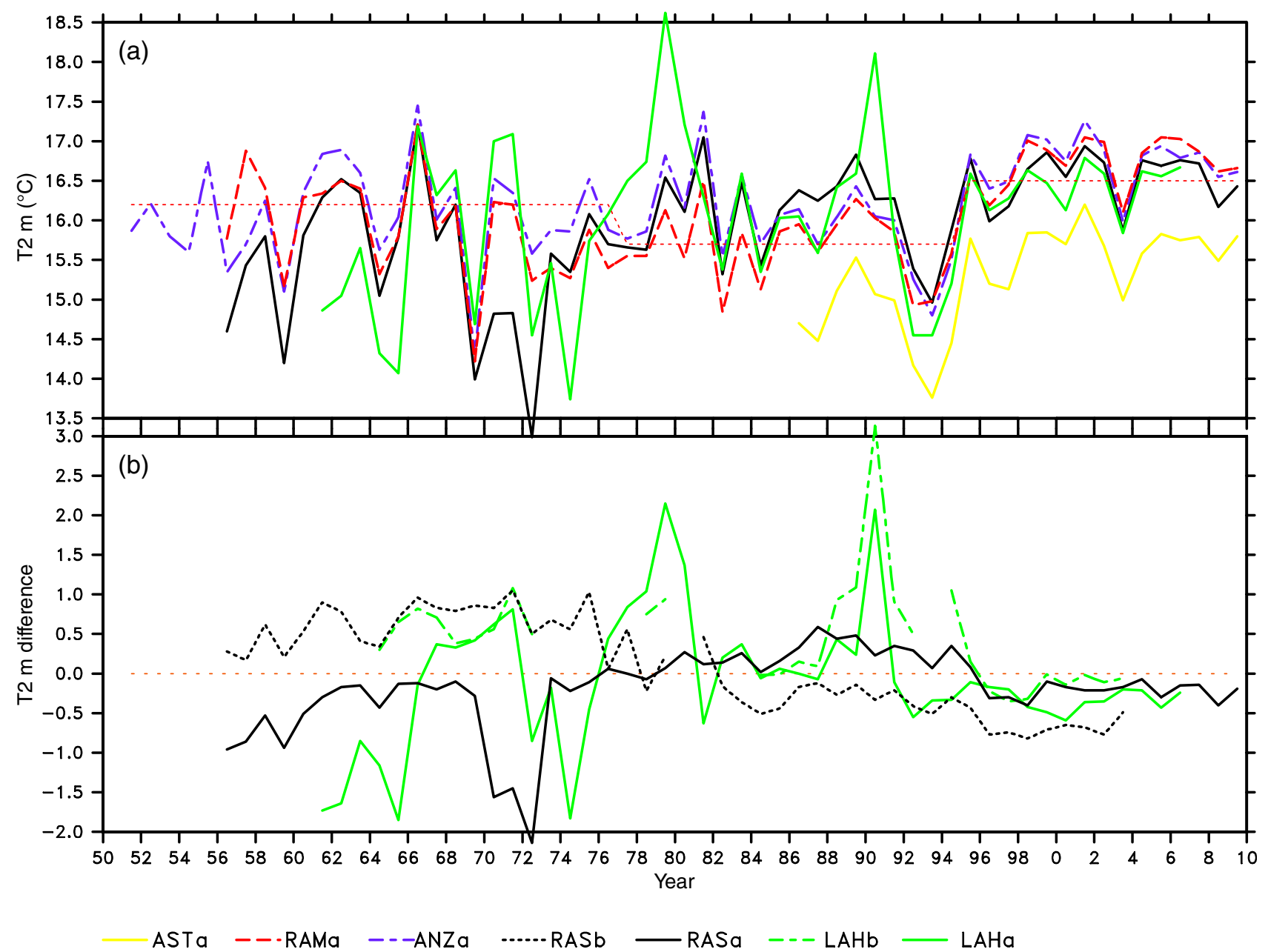

Figure 6. Time series of annual mean $2 \mathrm{~m}$ temperatures at four stations: (a) Anzali (ANZa), Rasht (RASa), Lahijan (LAHa), Ramsar (RAMa) and Astara (ASTa). (b) Difference between Rasht (RASa and RASb) or Lahijan (LAHa and LAHb) and the mean of Anzali and Ramsar (ANZa and RAMa) stations. The last letter indicates the source of the data. Units for T2m: ${ }^{\circ} \mathrm{C}$. In (a), auxiliary lines $\left(16.0 / 15.8 / 16.5^{\circ} \mathrm{C}\right)$ are provided for easier visual recognition of long-term means.

1994. In 1995, the CSL changed its direction from a steep rise to a moderate decline, which had been associated with Arpe et al. (2000) with a change in the ENSO signature. Further possible connections with ENSO are discussed below. In addition, a drop of $\mathrm{T} 2 \mathrm{~m}$ is observed around the year 1969 in all stations (Figure 6(a)) by about $2{ }^{\circ} \mathrm{C}$. Also Table 3 singles out this year as having extremely low temperature values. But at Anzali as well as at Ramsar and Lahijan (but not for Rasht), the previous level is regained for the following years, settling at a level $0.5^{\circ} \mathrm{C}$ below the long-term mean before 1969. In Figure 7, which shows only two stations, the auxiliary lines visualise a drop of T2m in 1972 while in Figure 6(a) with all stations, the drop is more difficult to time. The year of increase (1995) is the same for all stations, while the year of drop differs slightly between the stations (1972-1977).

The trends calculated by a least-square deviation method (CDO, 2014) are provided in Table 2. Astara is not included as it has too short a time series. All stations show an increase of $\mathrm{T} 2 \mathrm{~m}$, with the strongest for Rasht. But it has been shown above that the Rasht data are doubtful before 1975 and therefore this trend value may be too large, especially as the data set (b) has values up to $1{ }^{\circ} \mathrm{C}$ higher than data set (a) in the $1960 \mathrm{~s}$ and values more than $0.5^{\circ} \mathrm{C}$ lower from 1982 onward (Figure 6(b)), which cancels the trend shown in Table 2 . The T2m values for Lahijan station were shown above to have unrealistic spikes and large differences from the older data set (b), especially in the early 1960s when the differences to Anzali and Ramsar are very large, and therefore its trend is doubtful. The increase of $\mathrm{T} 2 \mathrm{~m}$ is around $0.9^{\circ} \mathrm{C}$ in 55 years when taking only the reliable stations Anzali and Rasht into account. Also Figures 5 and 6(a) clearly show higher values for all stations during the last decade, though not a steady increase. This increase has to be compared with the smaller global mean T2m increase of $0.8^{\circ} \mathrm{C}$ during the last 55 years (Hansen et al., 2010; HANSEN DATA, 2014). So also in this respect, the chosen area is distinctive compared to the rest of the world.

Therefore, it is proven that most of the considered series are normal for all stations. The minimum and maximum temperatures are calculated by finding the minimal and maximal temperatures for each month that are then averaged for the year. The range between them represents in some way the variance of the temperature. According to 


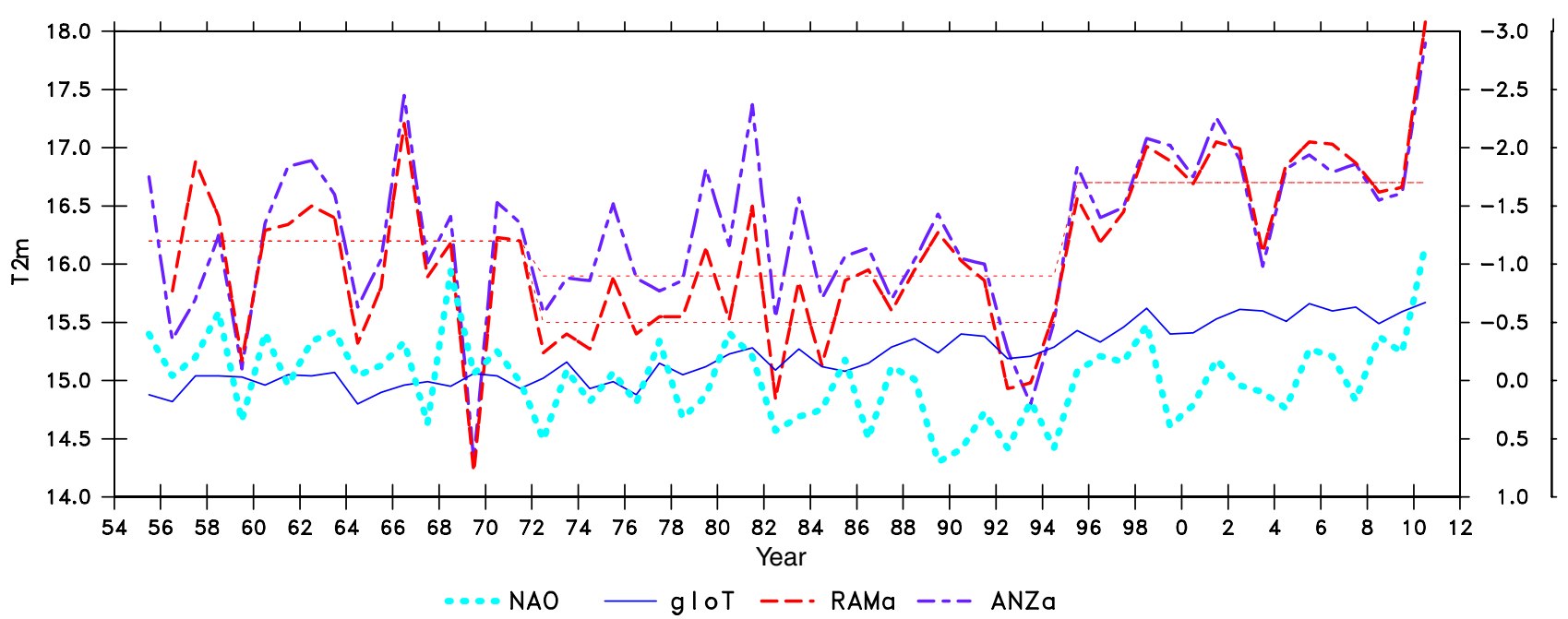

Figure 7. Annual mean T2m for Ramsar and Anzali compared with global temperature variability by Hansen et al. (2010). The latter are provided as anomalies and therefore $15^{\circ} \mathrm{C}$ have been added to fit the values of the other temperatures for easier comparison. Units of T2m: ${ }^{\circ} \mathrm{C}$ on left axis. Also the time series of NAO is provided [data from NCEP-NAO (2014)] but with a reversed scale provided on the right axis. Auxiliary lines of $16.2-16.0$ (or 15.5$)-16.7^{\circ} \mathrm{C}$ are provided to ease the visual detection of changes in the mean values.

Table 2. Mean change (trend) of the mean, minimum and maximum temperature and of the precipitation over 55 years at four stations (Astara is not included because of its short time series).

\begin{tabular}{|c|c|c|c|c|c|c|}
\hline & Anzali & Ramsar & Rasht & Lahijan & Anz/Ram or + Ras & Hansen T2m/GPCC \\
\hline Mean T2m trend $\left({ }^{\circ} \mathrm{C}\right)$ & $0.85 * *$ & $1.00 * *$ & $1.52 * *$ & $1.18 * *$ & $0.92 * *$ & $0.75 *$ \\
\hline Minimum $\mathrm{T} 2 \mathrm{~m}$ trend $\left({ }^{\circ} \mathrm{C}\right)$ & $2.59 * *$ & $1.74 * *$ & $2.65 * *$ & $3.80 * *$ & $2.13 * *$ & - \\
\hline Maximum T2m trend $\left({ }^{\circ} \mathrm{C}\right)$ & $-0.83 *$ & 0.40 & 0.30 & -1.49 & $-0.22 *$ & - \\
\hline Precipitation trend $(\mathrm{mm} / \%)$ & $-573 /-31 \% *$ & $-138 /-11 \%$ & $-74 /-6 \%$ & $+32 /+2 \%$ & $-261 /-18 \%$ & $-556 /-42 \% *$ \\
\hline
\end{tabular}

The trends of the global mean temperatures (Hansen et al., 2010) and the precipitation in the GPCC (2013) at a grid point for Anzali are given for comparison. Units: change during 55 years, for Lahijan this means some extrapolation.

*Significant at the 0.05 level.

$* *$ Significant at the 0.01 level.

Table 2, minimum temperature series have a significant upward trend for all stations, larger than that of the mean temperature, while the trend of the maximum temperature series have a statistically significant downward trend, but only for Anzali, while for the other stations the maximum temperatures rise or fall. Again one has to use the values of Rasht and Lahijan with care or not at all. It has often been said that with increasing greenhouse gases the extremes will increase, but this statistic does not support this view as both the minimum and maximum temperatures move towards the mean, i.e. the temperatures become less extreme. This does not fit with personal experience in which recent years seemed to have had extremely low temperatures with catastrophic snow events and with old trees dying because of sub-zero temperatures.

\subsection{Temperature extremes}

The definition of hot/cold years is made by means of $Z$-indices that are the normalized time series. A year or a season is defined as extremely hot when $\mathrm{Z}>1.9$ and as extremely cold when $Z<-1.9$. We have chosen these limits as a compromise in order to have a suitable number of cases. Other scientists have used other values (Wu et al., 2001). Hot/cold sequences at each station are identified and their timings are compared for Anzali, Ramsar, Rasht,
Lahijan and Astara in Table 3. Years of extreme events vary considerably for the different stations. Only 2010 is shown to have been extremely hot at all stations. In the same year, European Russia had an extremely hot and dry summer (Arpe et al., 2012). Such large-scale relationships will be discussed below. The year 1969 was extremely cold at all stations, but for Rasht and Lahijan these values were exceeded in 1972 and 1974, respectively; however, both were pointed out to be suspicious. Also the hot temperatures for Lahijan in 1979 are probably not real.

3.3. Comparison of time series of station values with ERA interim analyses

For a better interpretation, in this section we compare the time series of T2m for Anzali, Ramsar and Astara (Figure 8) as observed (OBS) or in the ECMWF interim reanalyses (ERA) (Dee et al., 2011; ECMWF, 2014) for a grid point (reduced Gaussian grid as used by ECMWF) representing the station. In many publications, the reanalysis data are used as true observations and here we want to see if it is justified for our area of interest. The temperatures from ERA had to be adjusted by $0.5^{\circ} \mathrm{C}$ for Anzali, $2.3^{\circ} \mathrm{C}$ for Ramsar and $0.3^{\circ} \mathrm{C}$ for Astara because in the ERA scheme the analysis is made at model levels. Some necessary smoothing of the steep orography in the area for 
Table 3. Extreme values of temperature with $Z$-indices $>1.9$ and $<-1.9$.

\begin{tabular}{|c|c|c|c|c|c|c|c|c|c|c|}
\hline \multirow[t]{2}{*}{ Event } & \multicolumn{2}{|c|}{ Anzali } & \multicolumn{2}{|c|}{ Ramsar } & \multicolumn{2}{|c|}{ Rasht } & \multicolumn{2}{|c|}{ Lahijan } & \multicolumn{2}{|c|}{ Astara } \\
\hline & Temperature & $Z$-index & Temperature & $Z$-index & Temperature & $Z$-index & Temperature & $Z$-index & Temperature & $Z$-index \\
\hline 1959 & 15.10 & -1.73 & 15.18 & -1.26 & 14.20 & -2.12 & - & - & - & - \\
\hline 1965 & 16.04 & -0.31 & 15.80 & -0.39 & 15.79 & -0.24 & 14.07 & -1.94 & - & - \\
\hline 1969 & 14.33 & -2.90 & 14.22 & -2.58 & 14.00 & -2.38 & 14.69 & -1.33 & - & - \\
\hline 1972 & 15.58 & -1.01 & 15.24 & -1.17 & 13.25 & -3.25 & 14.55 & -1.47 & - & - \\
\hline 1974 & 15.86 & -0.59 & 15.27 & -1.14 & 15.35 & -0.77 & 13.74 & -2.26 & - & - \\
\hline 1979 & 16.82 & 0.86 & 16.13 & 0.05 & 16.54 & 0.66 & 18.62 & 2.57 & - & - \\
\hline 1990 & 16.05 & -0.29 & 16.03 & -0.08 & 16.27 & 0.34 & 18.11 & 2.06 & 15.1 & -0.40 \\
\hline 1993 & 14.80 & -2.17 & 14.98 & -1.53 & 14.96 & -1.22 & 14.55 & -1.47 & 13.8 & -2.32 \\
\hline 2010 & 17.90 & 2.49 & 18.08 & 2.75 & 17.84 & 2.19 & - & - & 16.9 & 2.28 \\
\hline
\end{tabular}

Italic numbers are given for comparison for stations that are not extreme according to the $Z$-index in years when other stations are. Bold numbers are absolute extreme values for each station (hottest and coldest year 1955-2010). Dashes indicate years without information. Data from IRAN A (2014).

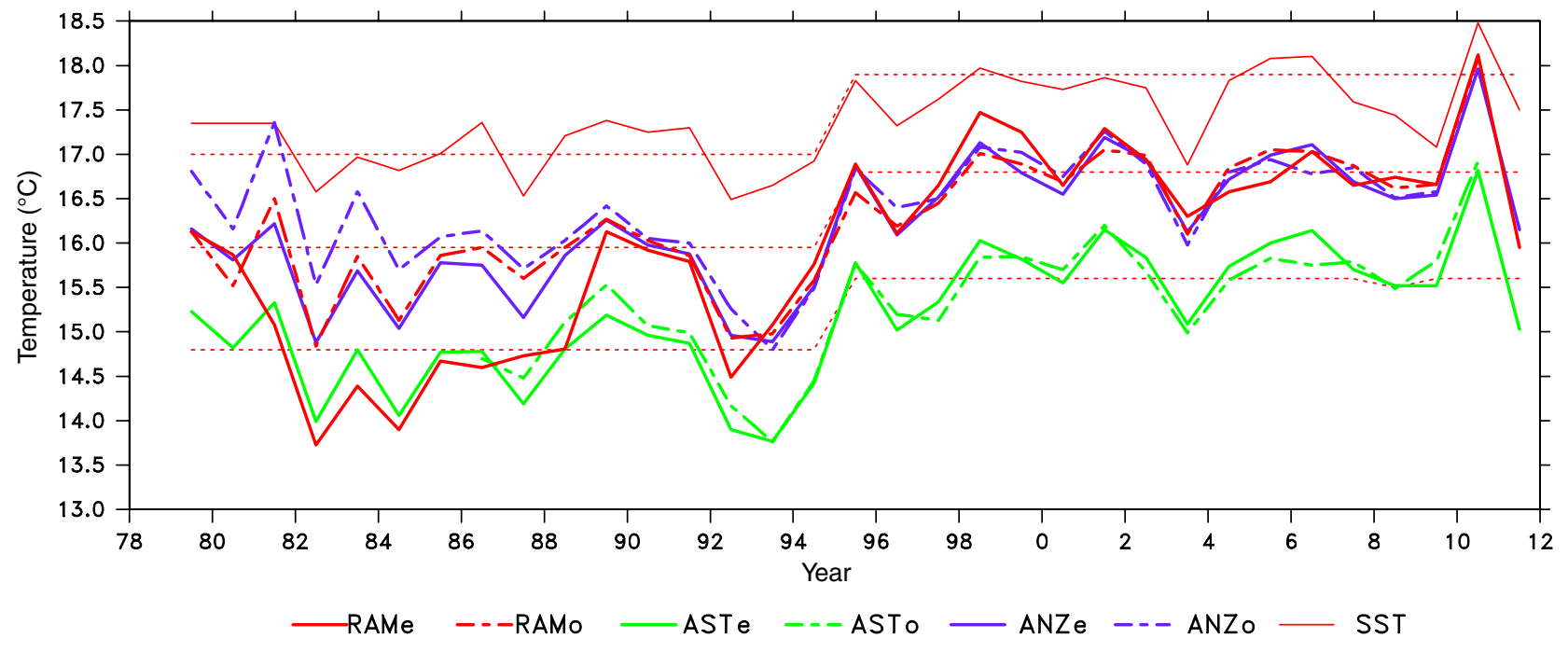

Figure 8. Time series of T2m for Anzali, Ramsar and Astara as observed at the stations (dashes - ANZo, RAMo and ASTo) and as analysed by ERA (solid - ANZe, RAMe and ASTe) for the grid point covering the respective station. The SST for the southern CS from ERA is given for comparison. Auxiliary lines are given with values: 17.0-17.9/16.0-16.8/14.8-15.6 for easing a visual estimate of the shifts in the mean values.

the model creates erroneous elevations at the grid points of 136, 838 and $272 \mathrm{~m}$ for Anzali, Ramsar and Astara, respectively. Therefore the observed values have to be interpolated to the model level and after the analysis they have to be extrapolated back to the real $2 \mathrm{~m}$ height, which can cause some biases (ECMWF-DOCU, 2014). The adjustments were made to obtain a good agreement between observational and ERA data for the period after 1988, i.e. the period when we have the most confidence in the quality of the data. This results in a bias for the previous years, i.e. $1979-1987$, of about $0.5^{\circ} \mathrm{C}$ warmer temperatures in the observations than in ERA for Anzali and up to $1.5^{\circ} \mathrm{C}$ for Ramsar. We have used the values at the grid covering the station instead of trying to interpolate the value exactly for the station because that would create some smoothing that might in turn create errors in situations like this where the neighbouring grid in one direction is a sea point and in the other direction a point high in the mountains.

The SST of the CS in ERA uses only climatological values before 1982 and less accurate estimates before the availability of Special Sensor Microwave Imager (SSMI)
(Kouraev et al., 2004) observations in 1988 (Figure 8). Therefore, the bias of T2m in the ERA data for the earlier period is probably due to this deficiency.

Some increases of temperature are noted but more in the form of a jump around 1995, rather than a steady trend. This is weaker in the station values than in the ERA data. Moreover, the SST over the southern CS shows a similar steep increase around 1995 as at the synoptic stations, but even stronger, i.e. by $0.9^{\circ} \mathrm{C}$ compared with 0.8 and $0.7^{\circ} \mathrm{C}$ (auxiliary lines in Figure 8 ). In brief, for our area the use of ERA data as true observations cannot be done straight away.

\subsection{Precipitation}

The time series of precipitation from the two data sources agree very well, so we need to investigate only one of them. We chose the IRAN A (2014) data because of its longer and more complete series. One finds a very similar variability at all stations for the annual means, though at different levels, with the highest for Anzali (Figure 9). The years of extreme events (Table 4), however, vary 


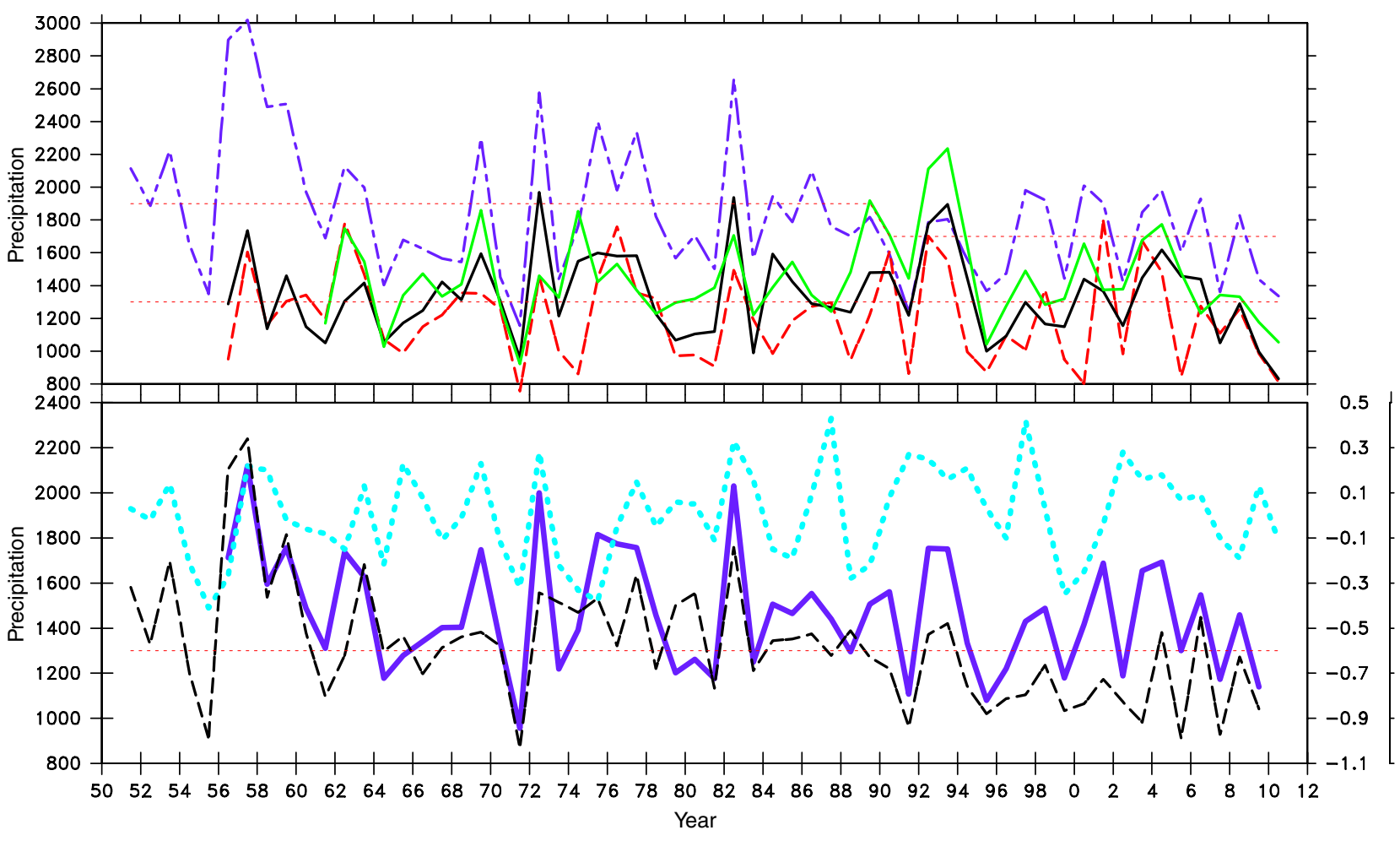

LAHa --RAMa --- ANZa $\longrightarrow$ RASa $--\cdot$ GPCC $\ldots$ ONI $\longrightarrow$ ARRm

Figure 9. Annual mean precipitation at Anzali, Ramsar, Lahijan and Rasht (upper panel) compared with precipitation analysed by GPCC on a $0.5^{\circ}$ grid for Anzali and a mean of the three stations Anzali, Ramsar, and Rasht (ARRm). Units of precipitation (left axis): mm year ${ }^{-1}$. For comparison also the $\mathrm{ONI}$ is included, with values given on the right axis.

Table 4. Extreme values of precipitation, $Z$-index and amounts of precipitation during extreme years.

\begin{tabular}{|c|c|c|c|c|c|c|c|c|c|c|}
\hline \multirow[t]{2}{*}{ Event } & \multicolumn{2}{|c|}{ Anzali } & \multicolumn{2}{|c|}{ Ramsar } & \multicolumn{2}{|c|}{ Rasht } & \multicolumn{2}{|c|}{ Lahijan } & \multicolumn{2}{|c|}{ Astara } \\
\hline & Precipitation & $Z$-index & Precipitation & $Z$-index & Precipitation & $Z$-index & Precipitation & $Z$-index & Precipitation & $Z$-index \\
\hline 1956 & 2898 & 2.47 & 951 & -0.96 & 1288 & -0.22 & & & & \\
\hline 1957 & 3020 & 2.76 & 1605 & 1.41 & 1735 & 1.50 & & & & \\
\hline 1962 & 2126 & 0.65 & 1781 & 2.05 & 1304 & -0.15 & 1749 & 1.12 & & \\
\hline 1971 & 1156 & -1.64 & 755 & -1.67 & 958 & -1.48 & 923 & -1.97 & & \\
\hline 1972 & 2575 & 1.71 & 1457 & 0.88 & 1968 & 2.39 & 1410 & 0.04 & & \\
\hline 1976 & 1982 & 0.31 & 1758 & 1.97 & 1579 & 0.90 & 1532 & 0.31 & & \\
\hline 1982 & 2662 & 1.92 & 1494 & 1.01 & 1937 & 2.28 & 1707 & 0.96 & & \\
\hline 1992 & 1785 & -0.15 & 1701 & 1.76 & 1776 & 1.66 & 2111 & 2.48 & 1434 & 0.43 \\
\hline 1993 & 1805 & -0.10 & 1550 & 1.21 & 1895 & 2.11 & 2236 & 2.94 & 1392 & 0.23 \\
\hline 2000 & 1930 & 0.38 & 803 & -1.50 & 1438 & 0.36 & 1656 & 0.77 & 1930 & 2.81 \\
\hline 2001 & 1904 & 0.13 & 1794 & 2.10 & 1365 & 0.08 & 1373 & -0.29 & 1479 & 0.65 \\
\hline 2010 & 1336 & -1.21 & 814 & -1.46 & 831 & -1.97 & 1055 & -1.48 & 1199 & -0.69 \\
\hline 2011 & 2914 & 2.51 & 1415 & 0.72 & 1825 & 1.84 & 1761 & 1.16 & 1323 & -0.10 \\
\hline
\end{tabular}

Italic numbers are given for comparison for stations that are not extreme according to the $Z$-index $(<-1.9$ or $>1.9)$ in years when other stations are. Bold numbers are absolute extreme values for each station (driest year and rainiest years). Dashes indicate years without information. Data from IRAN A (2014).

considerably between the different stations. The year 1971 is the only year with extremely low precipitation amounts at all stations, though for Rasht the year 2010 was even dryer, also a year with very low precipitation amounts at all stations. Two auxiliary lines are added in Figure 9 to help judgement on the occurrence of trends. Only the Anzali station shows a clear downward trend but with more of a step change around 1990 by $200 \mathrm{~mm} \mathrm{(9 \% ).}$ None of the others agree with such a large drop and we would regard the Anzali time series for precipitation with the suspicion of having had a change in observational method or environmental conditions. However, below, it is shown that this suspicion may not be justified. The trend value of precipitation for Anzali is not very stable, e.g. by eliminating successively the values from 1956 to 1959; the trend is reduced further and further to half of that for the full time series. This does not happen when eliminating the last four values of the time series successively. Table 2 
confirms that only Anzali has a strong downward trend with Ramsar second in strength, while Lahijan has a slight upward trend. In Table 2, the trend for Anzali precipitation is indicated to be statistically significant at the 0.05 level but being so much dependent on using the few values at the beginning of the time series put some doubt on its accuracy.

The trends vary for the stations in respect to the relative position between the sea and the mountains. Anzali, next to the sea, has the highest downward trend and Lahijan, next to the mountains, a slight upward trend, and the other two stations fit well into this variation. Ramsar is the most difficult station in this respect, as there the sea is only a very short distance away from the mountains. Raziei et al. (2014a) investigated trends in the precipitation over Iran. Their only common station with our investigation is Rasht, where they find an upward trend of $0.66 \mathrm{~mm} \mathrm{year}^{-1}$ (or $36 \mathrm{~mm} / 55$ years) for the period 1961 -2004, while a downward trend of $-74 \mathrm{~mm} / 55$ years occurs over the longer period used in this study (Table 2). When using our data for the period 1961-2004 only, the trend becomes positive, +1.4 mm year $^{-1}$ (or $77 \mathrm{~mm} / 55$ years). Also Rahimzadeh et al. (2009) provide trends of precipitation for Rasht. Their calculations are based on the data 1956 to 2003 and give a value of +0.16 mm year $^{-1}$, which is half the value we arrive at when repeating the calculation with our data. These differences show why in Table 2 the precipitation trends for Rasht (and others) are marked as being less statistically significant.

Figure 9 includes the time series of precipitation as analysed by GPCC (Schneider et al., 2011; Becker et al., 2013; GPCC, 2013) for the grid point covering Anzali. GPCC uses the IRAN B (2007) data (Fuchs et al., 2007). The GPCC values are lower than those at the stations themselves, as the analysis should represent an area average for the grid point provided on a $0.5^{\circ}$ grid and also takes observations further away into account. The grid point of Anzali covers an area with stations that have less precipitation than Anzali itself. The GPCC shows a steady slow downward trend in precipitation, which is not supported by the observed data used here. The precipitation time series of GPCC shows a decrease of about $556 \mathrm{~mm}$ in 55 years at a mean value of $1325 \mathrm{~mm}$, i.e. $42 \%$. This decrease is stronger than in any of the station time series given in Table 2. Using analysis data for trend analysis has some problems because an increase or decrease in available data can cause artificial changes (Bengtsson et al., 2004). For example in 1993 the data of the station Manjil, only $50 \mathrm{~km}$ south of Rasht, became available. It has very low precipitation amounts because it lies in the mountains. It was therefore expected to cause a drop in the analysed precipitation for the grid point covering Rasht and Anzali and indeed the general drop of precipitation in GPCC over the years is slightly enhanced around that year. The impact from the availability of observational station can also be seen in the 1950s. In the years before 1960, the GPCC data for Anzali have clearly higher values than later and variabilities very similar to that of Anzali station itself. In those days, the nearest observational stations for the Anzali grid point were only Anzali itself and stations far away like Tehran, Babolsar and one station between Ardabil and Astara, or either of them. After 1960, the number of available stations increased considerably making for a smoother and more confident analysis but also with lower values because the other stations in or near the grid report lower values than Anzali. That might be the reason for the strongest decrease from the 1950s to 1960s in the GPCC data. Above the drop of precipitation at the Anzali station around 1990 was regarded as suspicious but in Figure 9(b) also the GPCC data show such a drop. As the GPCC are based on a variety of station values, the suspicion on the Anzali data may be less justified. The downward trend of precipitation can be seen in GPCC and all station observations except for Lahijan. Above, it has been shown that the trends can change considerably with the length of the time series and our longer time series provide more reliable trends than those by Raziei et al. (2014b) and Rahimzadeh et al. (2009). The downward trend is opposite to the general global trends that are mostly upward in areas of abundant precipitation, like our study area, and downward in areas of little precipitation (e.g. Arpe and Leroy, 2007) though this area lies in the zonal belt of general decline of precipitation.

\subsection{Precipitation extremes}

The definition of extremely rainy or low rain (dry) years is made in the same way as for temperature (Table 4). Years of extreme events vary considerably for the different stations. The year 2010 was shown above to have been extremely hot at all stations and, for such events, one also expects a low precipitation amount. This is illustrated in Table 4 but not for all stations with extremely low precipitation. The year 1971 is the only year with extremely low precipitation amounts at all stations although for Rasht the value is exceeded in 2010 .

\section{Discussion}

\subsection{Connections with large-scale phenomena}

It was mentioned above that the very warm year, 2010, of the southwest CS (Table 3) coincided with the extremely hot and dry summer of 2010 over European Russia, which suggests a large-scale relationship. Also the snow cover variability over European Russia seems to be connected with the T2m variability in our study area.

Enhanced snow cover (i.e. cooler temperatures) over Russia during March to May (MAM) was found for the period 1978-1995, i.e. the years with lower T2m in the southwest CS, and a reduced snow cover for 1996-2010, i.e. the years with higher $\mathrm{T} 2 \mathrm{~m}$ in the southwest CS (Figure 10). In time series of snow cover over European Russia (Figure 11), the drop of snow cover is greatest around 1997-1998 but also shows clearly the drop from the 1990s to 2000s. So the lower T2m values 1984 to 1995 are part of a very large-scale phenomenon.

In Figure 11, T2m averaged for Anzali and Ramsar is included with a reversed scale to obtain the same tendency as the snow cover for easier comparison. The snow extent 

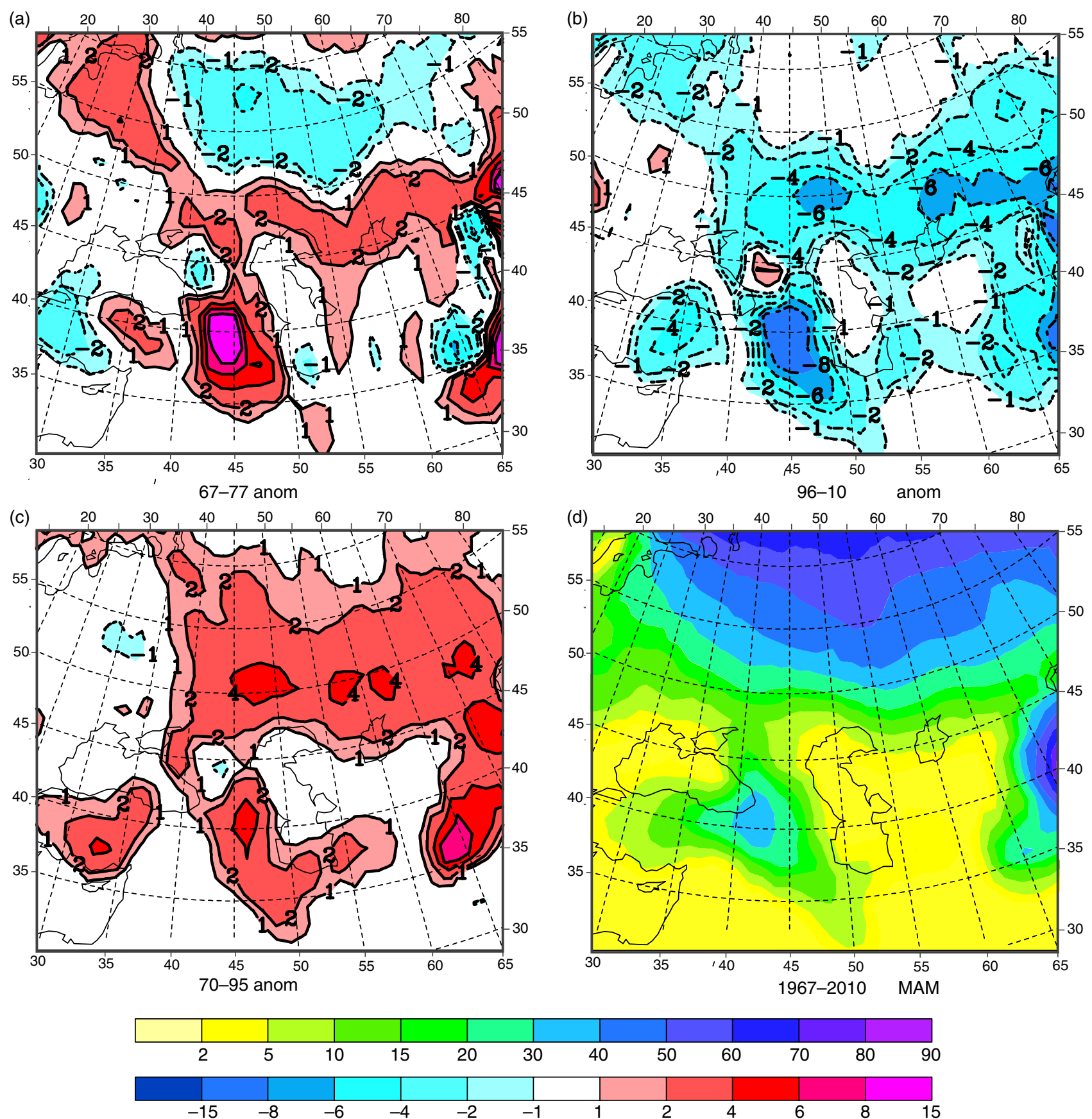

Figure 10. Mean snow cover measured by satellite during March to May (MAM) (d) and their anomalies for three periods, 1967-1977, 1978-1995 and 1996-2010 (a to c). Units: \% of area covered by snow [data from Robinson et al. (1993) and SNOW (2014)]. Negative contours are dashed. The upper scale bar is for the mean field (d) and the lower bar for the anomalies.

over European Russia shows a similarity with T2m at the stations along the southwest coast of the CS. The anomaly correlations between $\mathrm{T} 2 \mathrm{~m}$ and the annual mean snow cover is -0.47 , though quite a large part of it comes from the trend (Figure 11). By removing the impact from the mean trend (by using the anomaly correlation of their tendencies), it drops to 0.10 for the annual mean or 0.26 for the MAM snow cover.

In brief, the connection between $\mathrm{T} 2 \mathrm{~m}$ of the $\mathrm{SW}$ coast of the CS and the temperatures over European Russia are not strong but some evidence of it has been shown.

\subsection{Connections with ENSO, NAO and NCP}

The Ocean Nino Index (ONI) derived from NCEP-ENSO (2014) is scaled in such a way that it fits into the plot for the precipitation amounts in Figure 9(b). High values mean El Niño situations and low values La Niña. On quite a few occasions, the precipitation as well as the ONI values is extreme in the same year. In Table 5, the correlation coefficients between the anomalies of ONI and the single precipitation time series are shown. To avoid any contributions from possible trends, the correlations are included after calculating the difference between two 


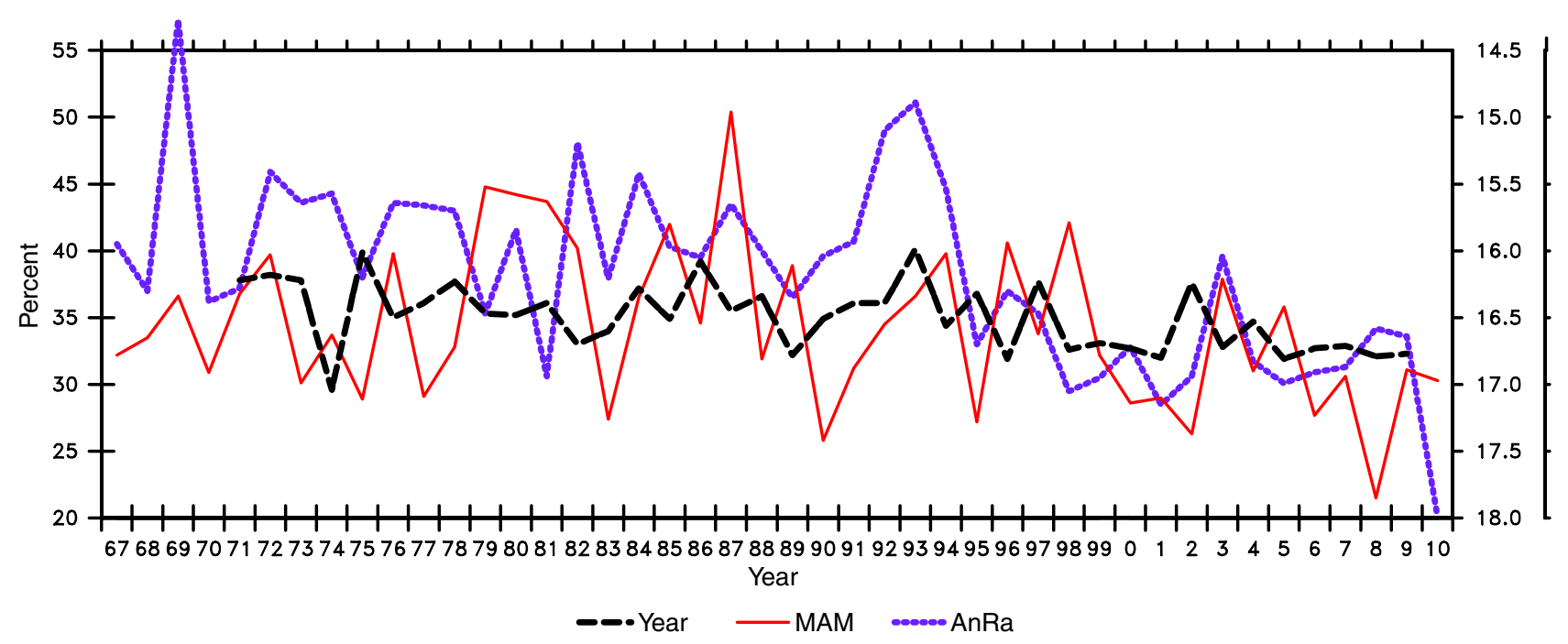

Figure 11. Time series of snow cover over European Russia $\left(41-65^{\circ} \mathrm{N}, 46-60^{\circ} \mathrm{E}\right)$ for annual and March to May (MAM) means. Also the mean T2m of Anzali and Ramsar (ARMm) with a reversed scale to fit the values of snow cover is included. Units on left axis for snow: \% of area covered by snow; units on the right for $\mathrm{T} 2 \mathrm{~m}$ in ${ }^{\circ} \mathrm{C}$.

Table 5. Correlations between time series of precipitation and the indices ONI, NAO and NCP.

\begin{tabular}{lcccccc}
\hline & Anzali & Ramsar & Rasht & Lahijan & Anz + Ram + Ras mean & GPCC \\
\hline Straight correlation ONI & $0.23^{*}$ & $0.28^{*}$ & $0.27^{*}$ & $0.21^{* *}$ & $0.27^{*}$ & $0.25^{*}$ \\
Tendency correlation ONI & $0.40^{*}$ & $0.25^{*}$ & $0.37^{*}$ & $0.21^{* *}$ & $0.41^{*}$ & $0.36^{*}$ \\
Straight correlation NAO & $0.08(0.05)^{* *}$ & $0.12(0.09)^{*}$ & $0.42(0.42)^{*}$ & $0.39(0.33)^{*}$ & $(0.2)^{*}$ & $(-0.07)^{* *}$ \\
Tendency correlation NAO & $0.21(0.22)^{*}$ & $0.03(0.15)^{*}$ & $0.29(0.35)^{*}$ & $0.24(0.22)^{*}$ & $(0.30)^{*}$ & $(0.16)^{*}$ \\
Straight correlation NCP & $0.09^{* *}$ & $0.17^{*}$ & $0.28^{*}$ & $0.19^{* *}$ & $0.20^{*}$ & $-0.11^{*}$ \\
Tendency correlation NCP & $0.05^{* *}$ & $0.09^{* *}$ & $0.06^{* *}$ & $-0.14^{* *}$ & $0.07^{* *}$ & $0.00^{* *}$ \\
\hline
\end{tabular}

Correlations with NCP and those in brackets cover only the period 1958 to 1998, while others are for 1956 to 2010.

* Significant at the 0.05 level. **Significant at the 0.01 level.

successive years (tendency), which serves as a high-pass filter. The latter gives higher values, suggesting that there is a connection on shorter time scales and that some trends, not obvious in the figure, might adversely affect the straight correlations. To improve the signal-to-noise ratio, we also averaged the time series of different stations. The straight correlation between precipitation at the stations and ONI is around 0.2 when we disregard Astara because of its short time series. This value is increased to around 0.35 for the tendency correlation and to 0.41 when averaging first the precipitation time series of Anzali, Ramsar and Rasht or to 0.36 when using GPCC data instead. Ghasemi and Khalili (2008b) reached even higher correlation coefficients by using principal components (PC4), which is also a way of increasing the signal-to-noise ratio and they used only winter data. Anzali has been included here, although it was pointed out above as possibly suffering from an inconsistency (i.e. a drop in 1990) that seems not to have a large impact on the correlations and, because of the similarity in the variability with the GPCC data at that time we are less concerned about this drop.

In Table 5, the correlations with NCP are also included. The latter values are taken from Table 1 of Kutiel and Benaroch (2002). As mentioned in the introduction, NCP and NAO are strongly impacted by the blocking over Europe. Therefore, the correlation between both is quite high, with 0.40 , and it is not surprising that both give similar values in Tables 5 and 6 . As the NCP time series is shorter than that of NAO, we have calculated the correlations with NAO for both time periods to give an impression about the impact on them from the length of the time series, which turns out to be of less importance.

The time series of temperatures (Table 6) do not show an obvious connection with ENSO, such as is found for the time series of precipitation. The ENSO signal is strongest in winter and therefore one can expect a clearer connection when investigating winter temperature data or annual temperature means from July to June the following year. However, such change of season did not increase the correlation coefficients. The correlations to the Rasht and Lahijan time series are included for comparison, although they were identified above as having some problems. The somewhat lower correlations for these stations may be due to these problems. Contrary to the precipitation, ENSO does not seem to be the main forcing for the temperature variability, as the correlations between ONI and T2m are only around -0.2 for the tendency correlation.

Higher precipitation is mostly associated with low surface pressure and Ghasemi and Khalili (2008a) gained higher correlations of 0.43 to 0.57 than those reported here by correlating the Black Sea MSLP and the dominant precipitation variability along the CS coast (PC4). 
Table 6. Correlations between the time series of T2m and the indices ONI, NAO and NCP.

\begin{tabular}{lccccc}
\hline & Anzali & Ramsar & Rasht & Lahijan & Anz+Ram mean \\
\hline Straight correlation ONI & $-0.25^{*}$ & $-0.13^{*}$ & $-0.08^{* *}$ & $-0.07^{* *}$ & $-0.19^{*}$ \\
Tendency correlation ONI & $-0.24^{*}$ & $-0.16^{*}$ & $-0.19^{*}$ & $-0.22^{*}$ & $-0.21^{*}$ \\
Straight correlation NAO & $-0.43(-0.41)^{*}$ & $-0.47(-0.44)^{*}$ & $-0.29(-0.24)^{*}$ & $-0.14(-0.14)^{*}$ & $-0.46(-0.44)^{*}$ \\
Tendency correlation NAO & $-0.42(-0.45)^{*}$ & $-0.45(-0.45)^{*}$ & $-0.45(-0.51)^{*}$ & $-0.32(-0.33)^{*}$ & $-0.44(-0.47)^{*}$ \\
Straight correlation NCP & $-0.48^{*}$ & $-0.43^{*}$ & $-0.44^{*}$ & $-0.28^{*}$ & $-0.47^{*}$ \\
Tendency correlation NCP & $-0.40^{*}$ & $-0.42^{*}$ & $-0.35^{*}$ & $-0.40^{*}$ & $-0.42^{*}$ \\
\hline
\end{tabular}

Correlations with NCP and those in brackets cover only the period 1958 to 1998, while others are for 1956 to 2010.

*Significant at the 0.05 level.

**Significant at the 0.01 level.

To check also such connections, we investigate teleconnection maps between precipitation time series used above and the mean sea level pressure (MSLP) (ERA40 - Uppala et al., 2005) at each grid point for the period 1958-2001, the maximum available in the ERA40 data. The tendency correlation is applied to reduce the impact from trends in the time series. Indeed, one finds high local correlations of more than 0.5 extending to the Black Sea for the precipitation (Figure 12(a)). Also a NAO-like signal can be seen with correlations exceeding 0.3. Their extremes are positioned west of the observational points used for calculating the NAO index. When making a teleconnection map between the NAO and the MSLP (not shown) one gets very similar patterns west of the CS, suggesting that the NAO plays an important role for the variability of precipitation along the southern CS coast. We regard the high correlations $(>0.5)$ in the tropical Pacific area together with correlations of opposite sign over the maritime continent, which is the signal of the Southern Oscillation, as more important and it agrees with the correlations in Table 5.

In Figure 12(b), a similar teleconnection map is shown as in Figure 12(a) but using the $500 \mathrm{hPa}$ height fields instead of the MSLP. A wave train from the Atlantic via Scandinavia to Iran is clearly indicated, which is associated with the Omega pattern mentioned in the introduction (a Scandinavian high is occurring together with troughs over Iberia and the Middle East). The Scandinavian-Middle East part is also reflecting the NCP connection, which can be regarded as part of the Omega pattern. Moreover the NAO pattern can be seen at this level and bears many similarities with teleconnection maps between the NAO and the $500 \mathrm{hPa}$ height fields. The connection with ENSO is however hardly indicated at this level.

For T2m (Figure 12(c)), a signal like the one from the Southern Oscillation, though shifted further to the central Pacific (therefore only low correlation values in Table 6) can be found. The NAO signal is very clear with values up to 0.45 , confirming the correlations between NAO and $\mathrm{T} 2 \mathrm{~m}$ in Table 6 . The high negative correlation around the Ukraine is part of the NAO, which can be seen by a teleconnection map between the NAO and the MSLP (not shown). It means that $\mathrm{T} 2 \mathrm{~m}$ at the southern CS is high when the MSLP is low west of it, implying southerly winds over Iran which can be assumed to carry hot air.
The correlations between $\mathrm{T} 2 \mathrm{~m}$ at our study area and the $500 \mathrm{hPa}$ height field (Figure 12(d)) show again the NAO signal over the Atlantic exceeding 0.5, and it shows the signal from the Omega pattern over Europe. The latter means that $\mathrm{T} 2 \mathrm{~m}$ is low when the $500 \mathrm{hPa}$ field is high over Scandinavia and low over northern Africa/Middle East, implying a weakened subtropical jet. The strongest signal occurs east of the CS. High $500 \mathrm{hPa}$ height field values there mean mostly low MSLP values west of it, which can be found in Figure 12(d) which imply southerly winds from Iran to the CS.

The correlations between $\mathrm{T} 2 \mathrm{~m}$ at the CS southern coast and $\mathrm{T} 2 \mathrm{~m}$ at all grid points (Figure 12(e)) gives of course the highest values $>0.9$ at the target area. Values $>0.5$ reach far to the north, east and west. It means that when it gets hot (cold) over the southern CS, it gets hot (cold) over a very large area, confirming connections like that with the snow cover over Russia shown above. It is connected with a large-scale trough-ridge pattern between Scandinavia and east of the CS as shown in Figure 12(d). The high negative correlations between $\mathrm{T} 2 \mathrm{~m}$ at the CS coast and the most northern Atlantic $(-0.5)$ are probably due to the low over Scandinavia with high T2m at the CS (Figure 12(c) and (d)), which implies north-easterlies over the northern Atlantic carrying cold Arctic air to the south.

Above, a clear connection between $\mathrm{T} 2 \mathrm{~m}$ at the study area and NAO is found with correlation coefficients about 0.46 (Table 6), while for precipitation that connection is much weaker. From Figure 7, it can be seen that the connection between $\mathrm{T} 2 \mathrm{~m}$ and NAO is not only present in the higher frequencies, but also the long-term changes around 1970 and 1990 in T2m are clearly indicated also in the NAO time series. This agrees with slightly lower correlations when using the tendency in Table 6.

A relationship of precipitation to ENSO, together with a connection of $\mathrm{T} 2 \mathrm{~m}$ with NAO, is unexpected as we assume that the precipitation and $\mathrm{T} 2 \mathrm{~m}$ are somehow correlated with high temperatures occurring together with low precipitation and vice versa, as found for 2010 and 1969. Mokhov and Smirnov (2006) found a relationship between ENSO and NAO with ENSO leading by 2 years. Indeed by correlating ENSO and NAO with our data and applying a 2-year time-shift, the tendency correlation coefficients increase from 0.06 to 0.32 . This relationship might explain our unexpected results, but it did not improve the correlation between $\mathrm{T} 2 \mathrm{~m}$ and ENSO when 

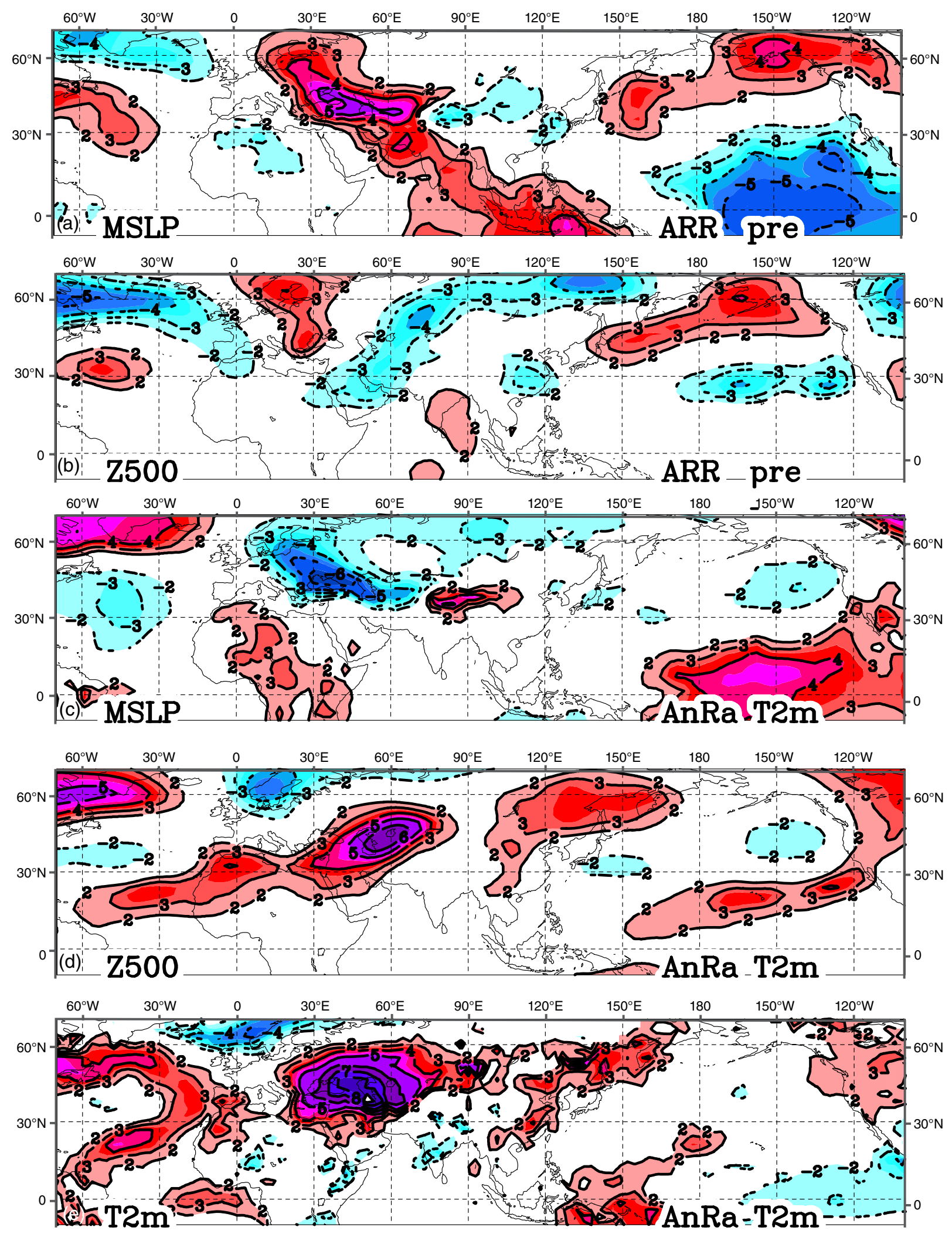

Figure 12. Teleconnection maps. (a) Correlation between the mean precipitation of Anzali, Rasht and Ramsar (ARR) and the MSLP at each grid point (ERA40 - Uppala et al., 2005) for the period 1958 to 2001. (b) Correlation between the mean precipitation of ARR and the MSLP using the $500 \mathrm{hPa}$ height for the period 1958 to 2002. (c) Correlation between the mean T2m of Anzali and Ramsar (AnRa) and the MSLP at each grid point (ERA40). (d) Correlation between the mean T2m of AnRa and the MSLP using the $500 \mathrm{hPa}$ height field. (e) Correlation between the mean T2m of AnRa and the MSLP using the T2m field. Dashed lines refer to negative correlations, for clarity of the plots, the correlation values are multiplied by 100 , so contours at $\pm 20,30,40,50,60$ refer to correlations at $\pm 0.2,0.3,0.4,0.5,0.6$. 
using a time-shift of 2 years. However, we found also for T2m a signal in the MSLP over the tropical Pacific (Figure 12(c)) with opposite signs with a slight shift to the west to the one for precipitation (Figure 12(a)) but for a real ENSO signal the dipole between the eastern tropical Pacific and the maritime continent is missing in Figure 12(c). A strong agreement between the water budget residuals and variations in climatological values implies that the CSL oscillations in the monthly to centennial time scale are essentially controlled by climate-related factors that have a strong connection with ENSO (Arpe et al., 2000; Ozyavas et al., 2010). Also in this study the connection between precipitation, a main component of the CS water budget, and ENSO becomes clear.

\section{Conclusions}

In this study, we have analysed climatic data from five synoptic stations in one of the regions with the highest precipitation levels of SW Asia. We identified some irregularities in the time series: (1) a drop in precipitation of 10\% around 1990 at Anzali, which is not followed by the other stations; (2) exceptionally low temperatures at Rasht 1971-1975 in the IRAN A (2014) time series (not in the IRAN B time series); (3) a negative bias of about $0.5^{\circ} \mathrm{C}$ for Rasht before 1971 compared to Anzali and Ramsar, and (4) large variations of T2m at Lahijan before 1992, less in the older data series (IRAN B, 2007). Also in the T2m data of the ECMWF interim reanalyses, two problems were identified: due to the strong orographic variations in the area, necessary interpolations and extrapolations lead to some biases in T2m, and inadequate knowledge of the SST of the CS before 1988 create some unrealistic T2m variabilities. We have contacted the data producers providing them with our findings for their information and possible corrections.

The main finding is that the $\mathrm{T} 2 \mathrm{~m}$ shows three distinct periods: 1956 to 1975 with values near to the overall mean; 1977 to 1995 with values $0.5^{\circ} \mathrm{C}$ lower and from 1996 to 2010 with values $0.5^{\circ} \mathrm{C}$ higher than the overall mean. All four stations agree with these changes, exactly for 1995, and with variations around 1975 . So what was special in these three periods? The T2m increase in 1995 is accompanied with an increase of the SST of the southern CS. This suggests that the CS SST is the driving force of T2m along the southwestern shores of the CS, which is reasonable because of the prevailing onshore surface winds. The T2m has a strong upward trend for the period 1977 to 2010. That trend becomes much weaker when including the data from 1956 onwards but still remains still stronger (around $0.9^{\circ} \mathrm{C}$ in 55 years $)$ than the global $\mathrm{T} 2 \mathrm{~m}$ trend $\left(0.8^{\circ} \mathrm{C}\right.$ for the same time period). We found strong inter-decadal variabilities, which stresses the need for very long time series to identify real trends in data and explains differences in trends reported by different authors. The similarity in the changes at all stations suggests that the differences before and after 1995 are due to atmospheric variability and not due to changes in the observational method. The years 1977 and 1995 coincide with the turning dates of the CSL - changes that have been shown previously to be related to ENSO and Volga River discharge variability. In 1995, the CSL reached its peak. Before that year the Volga had excessive precipitation and after that reduced precipitation (Arpe et al., 2000, 2014). The direct connection between T2m and ENSO is weak. Teleconnection maps show also a strong signal in the SST over the tropical Pacific but not over the eastern part, which would show the ENSO signal but more over the central Pacific. T2m has however a strong relationship with NAO.

Trends in precipitation are less coherent than those of temperature, Anzali showing the strongest downward trend followed by Ramsar and Rasht and with a slight upward trend at Lahijan. Bearing in mind that the drop in precipitation at Anzali around 1990 looks suspicious, we see a $5-10 \%$ drop over 55 years as a realistic value, which is only a third of what the GPCC data suggest for the grid point covering Anzali. The strong reduction of observational data during the earlier period may have contributed to this trend in GPCC. In general, precipitation has an upward trend in areas with abundant precipitation like our area and a downward trend in areas with low precipitation (Arpe and Leroy, 2007). Our study area does not follow that pattern. The time series of precipitation displays a much stronger connection with ENSO than does the temperature. This may be the same relationship as the CSL-ENSO relation. The connection between the precipitation and NAO variability is of opposite sign of that of $\mathrm{T} 2 \mathrm{~m}$ and much weaker.

Uncertainties in time series of single stations and large inter-annual variabilities can lead to contradictory results when calculating trends or correlations.

\section{Acknowledgements}

This article is a contribution to the European project Marie Curie, CLIMSEAS-PIRSES-GA-2009-247512: 'Climate Change and Inland Seas: Phenomena, Feedback and Uncertainties. The Physical Science Basis'. This research has also been supported by INIOAS in the framework of project no. 391-012-02. We are grateful to Mr Mike Turner (Brunel University) who has kindly revised the English of the manuscript and to Dr Majid Naderi for advising and giving useful comments. The anonymous reviewers provided us with valuable information and induced further useful thinking on the paper, we are grateful for their patience.

\section{References}

Akhani H, Djamali M, Ghorbanalizadeh A, Ramezani E. 2010. Plant biodiversity of Hyrcanian relict forests, N Iran: an overview of the flora, vegetation, palaeoecology and conservation. Pak. J. Bot. 42: $231-258$.

Arpe K, Leroy S. 2007. The Caspian Sea level forced by the atmospheric circulation, as observed and modelled. Quat. Int. 173-174: 144-152, doi: 10.1016/j.quaint.2007.03.008

Arpe K, Bengtsson L, Golitsyn S, Mokhov II, Semenov VA, Sporyshev PV. 2000. Connection between Caspian Sea level variability and ENSO. Geophys. Res. Lett. 27: 2693-2696. 
Arpe K, Leroy SAG, Mikolajewicz U. 2011. A comparison of climate simulations for the last glacial maximum with three different versions of the ECHAM model and implications for summer-green tree refugia. Clim. Past 7: 1-24, doi: 10.5194/cp-7-1

Arpe K, Leroy SAG, Lahijani H, Khan V. 2012. Impact of the European Russia drought in 2010 on the Caspian Sea level. Hydrol. Earth Syst. Sci. 16: 19-27, doi: 10.5194/hess-16-19-2012. http://www.hydrolearth-syst-sci.net/16/19/2012/ (accessed 21 August 2014).

Arpe K, Leroy SAG, Wetterhall F, Khan V, Hagemann S, Lahijani H. 2014. Prediction of the Caspian Sea level using ECMWF seasonal forecasts and reanalysis. Theor. Appl. Climatol. 117(1-2): 41-60, doi: 10.1007/s00704-013-0937-6.

Baidin S, Kosarev A. 1986. The Caspian Sea. Hydrology and Hydrochemistry. Moscow: Nauka (in Russian).

Becker A, Finger P, Meyer-Christoffer A, Rudolf B, Schamm K, Schneider U, Ziese M. 2013. A description of the global land-surface precipitation data products of the Global Precipitation Climatology Centre with sample applications including centennial (trend) analysis from 1901-present. Earth Syst. Sci. Data 5: 71-99, doi: 10.5194/essd-5-71-2013.

Bengtsson L, Hagemann S, Hodges KI. 2004. Can climate trends be calculated from re-analysis data. J. Geophys. Res. 109: D11111, doi: 10.1029/2004JD004536

Brunetti M, Kutiel H. 2011. The relevance of the North-Sea Caspian Pattern (NCP) in explaining temperature variability in Europe and the Mediterranean. Nat. Hazards Earth Syst. Sci. 11: 2881-2888, doi: 10.5194/nhess-11-2881-2011.

CDO. 2014. Climate Data Operators. https://code.zmaw.de/projects/cdo (accessed 21 August 2014).

De Jongh ILM, Verhoest NEC, De Troch FP. 2006. Analysis of a 105-year time series of precipitation observed at Uccle, Belgium. Int. J. Climatol. 26(14): 2023-2039.

Dee DP, Uppala SM, Simmons AJ, Berrisford P, Poli P, Kobayashi S, Andrae U, Balmaseda MA, Balsamo G, Bauer P, Bechtold P, Beljaars ACM, van de Berg L, Bidlot J, Bormann N, Delsol C, Dragani R, Fuentes M, Geer AJ, Haimberger L, Healy SB, Hersbach H, Hólm EV, Isaksen L, Kållberg P, Köhler M, Matricardi M, McNally AP, Monge-Sanz BM, Morcrette J-J, Park B-K, Peubey C, de Rosnay P, Tavolato C, Thépaut J-N, Vitart F. 2011. The ERA-interim reanalysis: configuration and performance of the data assimilation system. $Q$. J. R. Meteorol. Soc. 137(656): 553-597, doi: 10.1002/qj.828.

ECMWF. 2014. http://data-portal.ecmwf.int/data/d/interim_daily/ (accessed 21 August 2014).

ECMWF-DOCU. 2014. Chapter I, section 5.5.4 and Chapter IV, section 3.11.3. http://old.ecmwf.int/research/ifsdocs/CY31r1/index.html (accessed 21 August 2014).

Elliott RD, Smith TB. 1948. A study of the effect of large blocking highs on the general circulation in the northern-hemisphere westerlies. J. Meteorol. 6: 67-85.

Feng S, Hu Q, Qian W. 2004. Quality control of daily meteorological data in China, 1951-2000: a new data set. Int. J. Climatol. 24(7): $853-870$.

Fuchs T, Schneider U, Rudolf B. 2007. Global Precipitation Analysis Products of the GPCC. Global Precipitation Climatology Centre (GPCC): Offenbach, Germany.

Ghasemi AR, Khalili D. 2008a. The association between regional and global atmospheric patterns and winter precipitation in Iran. Atmos. Res. 88: 116-133.

Ghasemi AR, Khalili D. 2008b. The effect of the North Sea-Caspian pattern (NCP) on winter temperatures in Iran. Theor. Appl. Climatol. 92(4): 59-74.

GPCC. 2013. ftp://ftp-anon.dwd.de/pub/data/gpcc/html/download_gate. html (accessed 21 August 2014).

HANSEN DATA. 2014. http://data.giss.nasa.gov/gistemp/graphs_v3/ Fig.A2.txt (accessed 15 September 2014).

Hansen J, Ruedy R, Sato M, Lo K. 2010. Global surface temperature change. Rev. Geophys. 48: RG4004, doi: 10.1029/2010RG000345.

IPCC. 2013. Climate Change 2013: The Physical Science Basis. Contribution of Working Group I to the Fifth Assessment Report of the Intergovernmental Panel on Climate Change, Stocker TF, Qin D, Plattner G-K, Tignor M, Allen SK, Boschung J, Nauels A, Xia Y, Bex V, Midgley PM (eds). Cambridge University Press: Cambridge, UK and New York, NY, 1535 pp. doi: 10.1017/CBO9781107415324.

IRAN A. 2014. www.gilmet.ir/climate (accessed 21 August 2014).

IRAN B. 2007. www.irimo.ir/english (accessed 21 August 2014).

Kosarev AN. 2005. Physico-geographical conditions of the Caspian Sea. The Caspian Sea Environment. Springer: Berlin and Heidelberg, Germany.
Kosarev AN, Yablonskaya EA, IAblonskia EA. 1994. The Caspian Sea Vol. 20. SPB Academic Publishing: The Hague, The Netherlands. Kouraev AV, Papa F, Mognard NM, Buharizin PI, Cazenave A, Cretaux JF, Dozortseva J, Remy F. 2004. Sea ice cover in the Caspian and Aral Seas from historical and satellite data. J. Mar. Syst. 47(1): 89-100.

Kundzewicz ZW. 2004. Detection of change in world-wide hydrological time series of maximum annual flow report. WMO TD 1239, World Meteorological Organization, Geneva, Switzerland.

Kundzewicz ZW, Robson AJ. 2004. Change detection in hydrological records - a review of the methodology/revue méthodologique de la détection de changements dans les chroniques hydrologiques. Hydrol. Sci. J. 49(1): 7-19.

Kutiel H, Benaroch Y. 2002. North Sea-Caspian Pattern (NCP) - an upper level atmospheric teleconnection affecting the Eastern Mediterranean: identification and definition. Theor. Appl. Climatol. 71: $17-28$.

Kutiel H, Maheras P, Guika S. 1996. Circulation and extreme rain autumn conditions in the eastern Mediterranean during the last century. Int. J. Climatol. 16(1): 73-92.

Kutiel H, Maheras P, Türkeş M, Paz S. 2002. North Sea-Caspian Pattern (NCP) - an upper level atmospheric teleconnection affecting the eastern Mediterranean - implications on the regional climate. Theor. Appl. Climatol. 72(3-4): 173-192.

Leroy SAG, Roiron P. 1996. Final Pliocene macro and micro floras of the paleovalley of Bernasso (Escandorgue, France). Rev. Palaebot. Palynol 94: 295-328.

Leroy SAG, Lahijani HAK, Djamali M, Naqinezhad A, VahabiMoghadam M, Arpe K, Shah-Hosseini M, Hosseindoust M, Miller CS, Tavakoli V, Habibi P, Naderi BM. 2011. Late Little Ice Age palaeoenvironmental records from the Anzali and Amirkola Lagoons (south Caspian Sea): vegetation and sea level changes. Palaeogeogr. Palaeoclimatol. Palaeoecol. 302(3-4): 415-434.

Martin-Vide J, Lopez-Bustins JA. 2006. The western Mediterranean oscillation and rainfall in the Iberian Peninsula. Int. J. Climatol. 26 $1455-1475$.

Mokhov II, Smirnov DA. 2006. Study of the mutual influence of the El Niño-Southern Oscillation processes and the North Atlantic and Arctic Oscillations Izvestiya. Atmos. Oceanic Phys. 42(5): 598-614 (Original Russian Text in: Fizika Atmosfery i Okeana 42(5): 650-667).

Naderi Beni A, Lahijani H, Mousavi Harami R, Arpe K, Leroy SAG, Marriner N, Berberian M, Andrieu-Ponel V, Djamali M, Mahboub A, Reimer PJ. 2013. Caspian Sea-level changes during the last millennium: historical and geological evidence from the south Caspian Sea. Clim. Past 9: 1645-1665, www.clim-past.net/9/1645/2013/ (accessed 12 March 2013), doi: 10.5194/cp-9-1645-2013.

Nazemosadat MJ, Cordery I. 2000. On the relationship between ENSO and autumn rainfall in Iran. Int. J. Climatol. 20(3): 47-61.

Nazemosadat MJ, Ghasemi AR. 2004. Quantifying the ENSO-related shifts in the intensity and probability of drought and wet periods in Iran. J. Clim. 17(2): 4005-4017.

NCEP-ENSO. 2014. http://www.cpc.ncep.noaa.gov/products/analysis monitoring/ensostuff/ensoyears.shtml (accessed 21 August 2014).

NCEP-NAO. 2014. http://www.cpc.ncep.noaa.gov/products/precip/ CWlink/pna/norm.nao.monthly.b5001.current.ascii (accessed 21 August 2014).

Ozyavas A, Khan SD, Casey JF. 2010. A possible connection of Caspian Sea level fluctuations with meteorological factors and seismicity. Earth Planet. Sci. Lett. 299(1): 150-158.

Rafferty JP. 2011. Lakes and Wetlands. The Rosen Publishing Group, Britannica Educational Pub.: New York, NY.

Rahimzadeh F, Asgari A, Fattahi E. 2009. Variability of extreme temperature and precipitation in Iran during recent decades. Int. J. Climatol. 29: 329-343.

Raziei T, Daryabari J, Bordi I, Modarres R, Pereira LS. 2014a. Spatial patterns and temporal trends of daily precipitation indices in Iran. Clim. Change 124(1-2): 239-253.

Raziei T, Daryabari J, Bordi I, Pereira LS. 2014b. Spatial patterns and temporal trends of precipitation in Iran. Theor. Appl. Climatol. 115(3-4): $531-540$

Robinson DA, Dewey KF, Heim R Jr. 1993. Global snow cover monitoring: an update. Bull. Am. Meteorol. Soc. 74: 1689-1696.

Schneider U, Becker A, Finger P, Meyer-Christoffer A, Rudolf B, Ziese M. 2011. GPCC full data reanalysis Version 6.0 at 0.5 : monthly land-surface precipitation from rain-gauges built on GTS-based and Historic Data. DWD: Offenbach, Germany. doi: 10.5676/DWD_ GPCC/FD_M_V6_050.

SNOW. 2014. http://climate.rutgers.edu/snowcover (accessed 21 August 2014). 
Uppala SM, Kållberg PW, Simmons AJ, Andrae U, da Costa BV, Fiorino M, Gibson JK, Haseler J, Hernandez A, Kelly GA, Li X, Onogi K, Saarinen S, Sokka N, Allan RP, Andersson E, Arpe K, Balmaseda MA, Beljaars ACM, van de Berg L, Bidlot J, Bormann N, Caires S, Chevallier F, Dethof A, Dragosavac M, Fisher M, Fuentes M, Hagemann S, Hólm E, Hoskins BJ, Isaksen L, Janssen PAEM, Jenne R, McNally AP, Mahfouf J-F, Morcrette
J-J, Rayner NA, Saunders RW, Simon P, Sterl A, Trenberth KE, Untch A, Vasiljevic D, Viterbo P, Woollen J. 2005. The ERA-40 re-analysis. Q. J. R. Meteorol. Soc. 131: 2961-3012, doi: 10.1256/ qj.04.176.

Wu H, Hayes MJ, Weiss A, Hu Q. 2001. An evaluation of the Standardized Precipitation Index, the China-Z Index and the statistical Z-Score. Int. J. Climatol. 21(6): 745-758. 